\title{
Intrahippocampal Administration of Ibotenic Acid Induced Cholinergic Dysfunction via NR2A/NR2B Expression: Implications of Resveratrol against Alzheimer Disease Pathophysiology
}

\author{
Chennakesavan Karthick ${ }^{1}$, Sabapathy Periyasamy ${ }^{1}$, Kesavan S. Jayachandran ${ }^{2}$ and \\ Muthuswamy Anusuyadevi ${ }^{1 *}$
}

${ }^{1}$ Molecular Gerontology Laboratory, Department of Biochemistry (DST-FIST Sponsored), Bharathidasan University, Tiruchirappalli, India, ${ }^{2}$ Molecular Cardiology and Drug Discovery Laboratory, Department of Bioinformatics, Bharathidasan University, Tiruchirappalli, India

\section{OPEN ACCESS}

Edited by:

Robert J. Harvey,

University College London School of

Pharmacy, UK

Reviewed by:

Ganesh Ambigapathy,

University of North Dakota, USA

Tamilselvan Jayavelu,

Anna University, India

*Correspondence:

Muthuswamy Anusuyadevi msanushyas2005@gmail.com

Received: 04 February 2016 Accepted: 01 April 2016 Published: 26 April 2016

Citation:

Karthick C, Periyasamy S, Jayachandran KS and Anusuyadevi M (2016) Intrahippocampal

Administration of Ibotenic Acid Induced Cholinergic Dysfunction via NR2A/NR2B Expression: Implications

of Resveratrol against Alzheimer Disease Pathophysiology.

Front. Mol. Neurosci. 9:28.

doi: 10.3389/fnmol.2016.00028
Although several drugs revealed moderate amelioration of symptoms, none of them have sufficient potency to prevent or reverse the progression toward Alzheimer's disease (AD) pathology. Resveratrol (RSV), a polyphenolic compound has shown an outstanding therapeutic effect on a broad spectrum of diseases like age-associated neurodegeneration, inflammation etc. The present study was thus conducted to assess the therapeutic efficacy of RSV in ameliorating the deleterious effects of Ibotenic acid (IBO) in male Wistar rats. Stereotactic intrahippocampal administration of IBO $(5 \mu \mathrm{g} / \mu \mathrm{l})$ lesioned rats impairs cholinergic transmission, learning and memory performance that is rather related to $A D$ and thus chosen as a suitable model to understand the drug efficacy in preventing AD pathophysiology. Since IBO is an agonist of glutamate, it is expected to exhibit an excitotoxic effect by altering glutamatergic receptors like NMDA receptor. The current study displayed significant alterations in the mRNA expression of NR2A and NR2B subunits of NMDA receptors, and further it is surprising to note that cholinergic receptors decreased in expression particularly $\alpha 7$-nAChR with increased m1AChR. RSV administration (20 mg/kg body weight, i.p.) significantly reduced these changes in IBO induced rats. Glutamatergic and cholinergic receptor alterations were associated with significant changes in the behavioral parameters of rats induced by IBO. While RSV improved spatial learning performance, attenuated immobility, and improvised open field activity in IBO induced rats. NR2B activation in the present study might mediate cell death through oxidative stress that form the basis of abnormal behavioral pattern in IBO induced rats. Interestingly, RSV that could efficiently encounter oxidative stress have significantly decreased stress markers viz., nitrite, PCO, and MDA levels by enhancing antioxidant status. Histopathological analysis displayed significant reduction in the hippocampal pyramidal layer thickness and live neurons in IBO induced rats, with slight pathological changes in the entorhinal cortex $(E C)$ of rat brain, which was prevented 
on RSV administration. Our study thus concludes that RSV administration significantly ameliorated the deleterious effects in the IBO lesioned rat model for AD by alleviating cholinergic pathways, reducing oxidative stress and thereby improving spatial memory.

Keywords: ibotenic acid, hippocampus, Alzheimer's disease, NMDAR, acetylcholine receptors, memory, resveratrol

\section{INTRODUCTION}

Glutamate is the most prominent excitatory neurotransmitter involved in almost all central nervous system (CNS) functions, especially in cortical and hippocampal regions. Nearly $70 \%$ of all excitatory synapses in the CNS of mammalian brain utilize glutamate as a neurotransmitter. Glutamate receptors, in particular, $\mathrm{N}$-methyl $\mathrm{D}$-aspartate (NMDA) receptors are crucial for learning and memory processes. Normal healthy individuals utilize glutamatergic neurotransmission that acts via NMDA receptors to produce a long-term potentiation (LTP). LTP refers to strengthening of synapses through repeated use and is central to the processes of learning and memory, while acetylcholine $(\mathrm{ACh})$ and its receptors play a key role in both the induction and maintenance of LTP (Auerbach and Segal, 1994; Tai and Leung, 2012). ACh is released following depolarization to act on nicotinic and/or muscarinic receptors located on presynaptic cholinergic terminals, with neurotransmitter action being terminated by acetylcholinesterase (AChE). These information strongly emphasize the relationship between cholinergic and glutamatergic systems in cognitive aspects of brain function (Francis et al., 2012).

Hence, disturbances in glutamate neurotransmission may impact memory performance and has been linked with the pathophysiological processes underlying neurodegeneration and Alzheimer's disease (AD) (Wenk et al., 2006). AD is an ageassociated neurodegenerative disorder characterized by loss of memory and cognitive functions, associated with chronic and a progressive neurodegeneration (Gong et al., 2004; Citron, 2010). In AD, the number of glutamatergic pyramidal neurons is significantly reduced (Francis, 1993), while in AD atrophy, dysfunction of cholinergic and glutamatergic pyramidal neurons occurs such that remaining cortical neurons receive less innervation and consequently are less likely to be depolarized by synaptic signals (Francis et al., 2012) that may be the resultant of $\mathrm{A} \beta$ mediated excitotoxicty. Moreover, this could be accompanied by concomitant loss of glutamatergic neurons and abnormalities of NMDA receptor expression in hippocampus of $\mathrm{AD}$ patients.

Therapeutics against neurodegenerative diseases like AD has long been a quest for scientist. Preventing AD and complications due to formation and accumulation of amyloid plaques

\footnotetext{
Abbreviations: AD, Alzheimer's disease; CA, Cornu ammonis; CNS, Central Nervous System, IBO, Ibotenic acid; RSV, Resveratrol; NMDA, N-methyl Daspartate; NMDAR, N-methyl D-aspartate receptor; NR2A, N-methyl D-aspartate receptor 2A; NR2B, N-methyl D-aspartate receptor 2B; Ach, Acetylcholine; AChE, Acetylcholinesterase; $\alpha 7$-nAChR, $\alpha 7$-nicotinic acetylcholine receptor; GSH, Reduced glutathione; GPx, Glutathione peroxidase; MDA, Malondialdehyde; m1AChR, muscarinic acetylcholine receptor 1; nNOS, neuronal nitric oxide synthase; LTP, long term potentiation; LTD, long term depression; PCO, Protein carbonyl; RAM, Radial arm maze.
}

particularly $\mathrm{A} \beta$ mediated excitotoxicity and neurodegeneration has become a mystery until today. Several drugs have shown moderate amelioration of symptoms, while none of them have sufficient potency to prevent or reverse the progression toward AD pathology. Therefore, the drug of choice that could revert homeostatic events and reduce stress levels gains the appropriation. Therefore, the current study, employs resveratrol (RSV) or 3,5,4'-trihydroxystilbene, a type of naturally occurring polyphenolic compound commonly found in red grape skin is used as a potent therapeutic target. Recent drugs focus more on preventing pathophysiology that are a consequential event of $A \beta$ accumulation, but none could be successful in preventing one or other complications associated with $A \beta$ toxicity. Although RSV has proved for its antioxidant properties (Marambaud et al., 2005), homeostatic effects (Moorthi et al., 2015) and more, no reports are available on the action of RSV on glumatergic and cholinergic abnormalities associated with AD conditions.

Since the present study aimed at studying the efficacy of RSV in alleviating excitotoxic effects and neurodegeneration, Ibotenic acid (IBO) a potent neurotoxin that exacerbate the symptoms and pathological variations similar to $\mathrm{AD}$ patients (Zola et al., 2000; Ji et al., 2009; Clark et al., 2012) has been chosen as a suitable model to understand the drug efficacy in preventing $\mathrm{AD}$ pathophysiology. IBO is a dynamic NMDA receptor agonist when injected into the brain of animals can elicit severe injury and even death in neurons by inducing excessive calcium influx (Zhang et al., 2013) probably through receptor activation. Abnormally high concentrations of glutamate or its analog may promote prolonged stimulation of glutamate receptors, particularly $\mathrm{N}$-methyl-D-aspartate (NMDA) receptors in pathological conditions that could result in perturbed ion homeostasis, energy depletion, and the degeneration of neurons and cell death in a process called excitotoxicity (Antzoulatos and Byrne, 2004; Mattson, 2004). The current study was thus designed to determine whether RSV alleviates the pathological effects of IBO mediated neurodegeneration through susceptible receptors of major neuro-transmitter systems probably involved in learning and memory mechanisms and thereby assess the suitability of the drug in preventing $\mathrm{AD}$ like complications.

\section{MATERIALS AND METHODS}

\section{Chemicals}

All chemicals were procured from Sigma-Aldrich (St Louis, MO, USA) unless otherwise indicated. For RT-PCR, primers NR2A, NR2B, m1AChR, $\alpha 7$-nAChR, nNOS, and $\beta$-actin were obtained from Eurofins, Bangalore, India. Resveratrol were purchased from Cayman, Germany. Ibotenic acid was purchased from 
Abcam, Cambridge, UK. Acetylthiocholine iodide and DMSO from Hi-Media, India.

\section{Animals and Housing}

Male Wistar rats $(240 \pm 20 \mathrm{~g})$ were purchased from Sri Venkateshwara Enterprises, Bangalore, and maintained in the animal facility at Bharathidasan University, Tiruchirappalli, India. The experiments were performed in accordance with the Laboratory Animal Care Guidelines by the Committee for the Purpose of Control and Supervision of Experiments on Animals (CPCSEA) was followed. Experimental protocol used in this study was approved by the Institutional Animal Ethical Committee (BDU/IAEC/2014/OE/06/Dt.18.03.2014). Rats were individually housed with an alternative 12-h light/12-h dark cycle. All rats were given ad-libitum access to food and water.

\section{Generation of Memory Deficient Rat Model and Drug Treatment}

Stereotaxic surgery was performed by infusing IBO into the hippocampus of male Wistar rats. Briefly, rats were anesthetized by intraperitoneal injection of ketamine and xylazine and fixed on a stereotaxic apparatus (Ambala instrument, India). Intrahippocampal injection was made using $1.0 \mu \mathrm{l}$ Hamilton microsyringe (Hamilton-Reno, USA) and relative to the Bregma co-ordinates for the hippocampus were $-4.0,3.0 \mathrm{~mm}$ mediolateral, and $-3.6 \mathrm{~mm}$ for dorsoventral region of rats using Paxinos and Watson Atlas (sixth edition, 2007; Figure S1a). Confirmation on the infusion site was examined using trypan blue that displayed well-localized infusion to the dorsal hippocampus as shown in supplementary data, Figure S1b. Ibotenic acid was dissolved in phosphate buffered saline (PBS; $\mathrm{pH}$ 7.2) at a concentration of $5 \mu \mathrm{g} / 1 \mu \mathrm{l}$, then infused bilaterally into the hippocampus in a volume of $1.0 \mu \mathrm{l}$ at a rate of $0.1 \mu \mathrm{l}$ /min (Yu et al., 2012). After the injection, the needle was left in place for 5 min to prevent backflow. Sham-operated rats were given an injection of PBS instead of IBO solution. The skin was then sutured and the rats had fully recovered from anesthesia, and returned to their home cages. The treatment was started on post-operative day 3 with RSV ( $20 \mathrm{mg} / \mathrm{kg}$ body weight) for 15 days and control animals received the vehicle alone $(20 \%$ DMSO). Dosage fixation was modified based on protocols described by Zhang et al. (2009) and Zhao et al. (2013). Detailed study design is provided in Figure 1.

\section{Experimental Design}

Animals were randomly assigned into six groups with seven animals each,

Group I: Normal Control or intact animals that were left undisturbed.

Group II: Sham-operated control rats-PBS infusion.

Group III: Rats injected with IBO ( $5 \mu \mathrm{g} / \mu$ l PBS) bilaterally into hippocampus.

Group IV: Rats treated with RSV at dosage of $20 \mathrm{mg} / \mathrm{kg}$ body weight i.p., (dissolved in 20\% DMSO) following IBO injection. Group V: Rats treated with similar dose of RSV as described earlier.

Group VI: Vehicle control (20\% DMSO) administered rats.

\section{Behavioral Analysis by 8-Arm Radial Arm Maze (RAM) Task}

Behavioral analysis was performed as described by Olton and Samuelson (1976) with slight modifications. Rats were tested in a radial 8 -arm maze for the present study. It contains eight arms numbered from 1 to 8 , each arms $(48 \times 12 \mathrm{~cm})$ extending radially from a central area $(32 \mathrm{~cm}$ in diameter). The apparatus was placed $40 \mathrm{~cm}$ above the floor, and surrounded by various extra maze visual cues placed at the same position during the entire study. At the end of each arm there was a food cup that had a single $10 \mathrm{mg}$ food pellet (food reward).

Prior to the performance on the maze task for behavioral analysis, the animals were restricted to partial food deprivation schedule and body weight was maintained at $80 \%$ of their freefeeding weight over a week period, with water being available ad-libitum. Before the actual training began (habituation), three or four rats were simultaneously placed in the RAM task and allowed to explore the maze for $5 \mathrm{~min} /$ day for 2 days. The food rewards were randomly scattered over the entire maze surface. On 3rd day, four of the eight arms (no. 1, 3, 5, 7) were selected and food pellets were scattered. The other four arms (no. 2, 4, 6, 8) were never baited. On the 4 th day, pellets were placed in the food feeding cup at the end of the four baited arms. The number of baited arms and the spatial location of the baited arms relative to the room remained constant throughout the study. This provided the reference aspect of maze performance, where the rats were given five consecutive training trails per day for 8 days. The arm, first visited by the animal was observed.

After adaptation, to evaluate basal activity of rats in RAM task, rats were given five trials per day for 4 days during which a single food reward was placed in the food cup of the four arms assigned to be baited. Each rat was placed on the center platform facing randomly selected arms for each trial and allowed to make arm choices either of all four pellets were taken or until $5 \mathrm{~min}$ has elapsed. To prevent intra-maze cues (odor cues), the maze was cleaned (using 70\% ethanol) between each test. An arm entry was counted when all four limbs of the rat were within an arm. Measurements were made using the number of working memory errors (entering an arm containing food, but previously entered) and reference memory errors (entering an arm that was not baited) is considered as \% of correct response. The percentage of correct response was calculated by using the following formula,

$$
\begin{aligned}
\% \text { of correct response }= & \text { Number of correct response/ } \\
& \text { number of trials } * 100 .
\end{aligned}
$$

The latency period to enter the arm containing the food reward was recorded using a stopwatch. The time taken to consume all four baits was also recorded. All the behavioral experiments were carried out between 08.00 and $13.30 \mathrm{~h}$.

\section{Open Field Test}

The open field is used for measuring anxiety and exploration as well as locomotion as it has a large center arena. The open field apparatus was constructed of white plywood and measured 


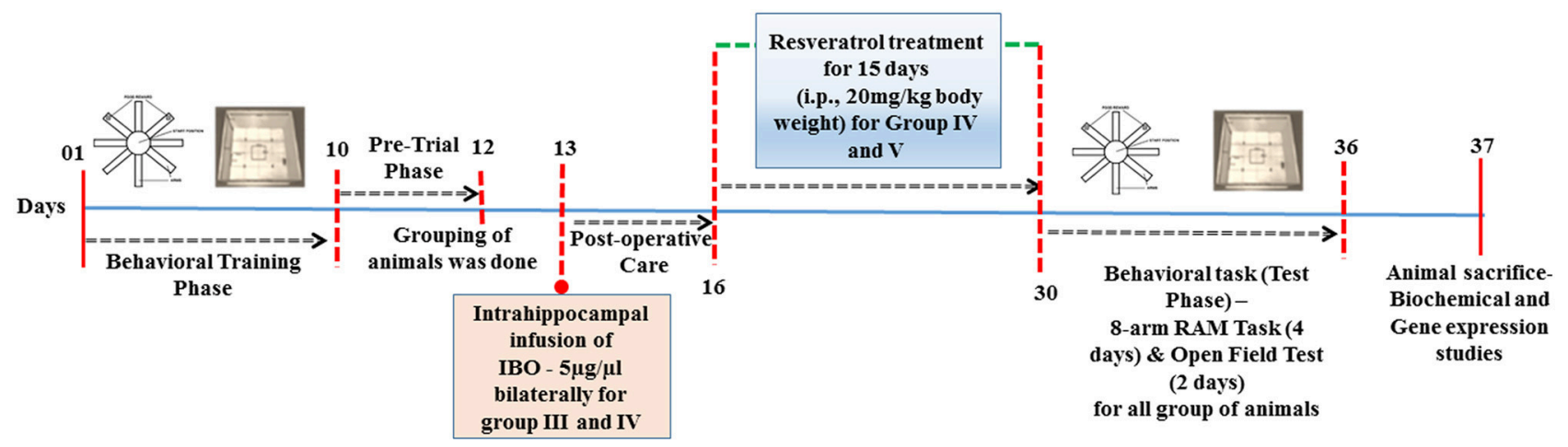

FIGURE 1 | Schematic representation of time-line for RSV treatment in IBO induced experimental animals.

$72 \times 72 \mathrm{~cm}$ with $36 \mathrm{~cm}$ walls. The lines divided the floor into sixteen of $18 \times 18 \mathrm{~cm}$ squares. A central square $(18 \times 18 \mathrm{~cm})$ was drawn in the middle of the open field (Brown et al., 1999). At the beginning of the open field session, rats were placed on the right front corner square (relative to the position of the experimenter). The animals were allowed to move freely about the open field for a period of $5 \mathrm{~min}$, and then returned to its home cage. The open field was cleaned with $70 \%$ ethyl alcohol and permitted to dry between tests. To assess the process of habituation to the novelty of the arena, rats were explored to the apparatus for $5 \mathrm{~min}$ on two consecutive days. The behavioral parameters measured was total number of grid crossings made during five trials per day for 2 days. A crossing was defined as all four paws moving out of one of the 16 squares and into another. This measure is expected to correlate highly with the distance traveled in the open field, and it reflects locomotor activity, exploratory behavior, head dipping, rearing, grooming, and anxiety (ambulations in number). Open field sessions were recorded and performance was analyzed after the testing took place.

\section{Tissue Collection and Processing}

After the behavioral tests, the rats from each group $(n=7)$ were killed by cervical decapitation and brain tissues were dissected out. Following dissection, each hippocampus $(n=4)$ was weighed and rapidly homogenized in 10 volumes of icecold homogenizing buffer for estimating protein, nitrite levels, protein carbonyl content and antioxidant assays, the remaining tissue was rapidly frozen in liquid nitrogen and stored at $-80^{\circ} \mathrm{C}$ for further analysis. Whole brain $(n=3)$ was removed for histopathological studies by fixing it in $10 \%$ phosphate buffered formalin at $\mathrm{pH} 7.2$.

\section{Histopathological Analysis}

Formalin fixed brain tissues were processed and stained with hematoxylin and eosin ( $\mathrm{H}$ and $\mathrm{E}$ ) based on the protocol described by Avwioro et al. (2010) with slight modifications. Tissues, 5 $\mathrm{mm}$ thickness were obtained from the rat brain. They were fixed in $10 \%$ phosphate buffered formalin for $24 \mathrm{~h}$ and processed for embedding with paraffin wax through ascending grades of alcohol (30, 50, 70, 90, and 95\%) for $1 \mathrm{~h}$ each, and two changes of absolute ethanol for $2 \mathrm{~h}$ each followed by two changes of xylene for $2 \mathrm{~h}$ each and two changes of paraffin wax at $60^{\circ} \mathrm{C}$ for $2 \mathrm{~h}$ each. Tissues were subsequently embedded in paraffin wax at about $60^{\circ} \mathrm{C}$. Sections were cut at $10 \mu$ thick with the microtome (Leica Instrument's). Six sections from each block were stained with hematoxylin and counter stained with $0.25 \%$ eosin. $\mathrm{H}$ and E stained sections were observed under light microscope and photomicrographs were captured (10x and $40 \mathrm{x}$ objective) throughout the stained sections for analyzing the morphological features of the hippocampus, entorhinal cortex, and amydgala of rat brain. Based on the observation, the images were selected and projected in the results.

\section{Extraction and Quantification of RNA}

Briefly, hippocampal tissue was homogenized and RNA was extracted using Trizol reagent for semi-quantitative RT-PCR analysis. Total RNA was solubilized in RNase-free $\mathrm{H}_{2} \mathrm{O}$, and quantified in duplicate by measuring the optical density (OD) at $260 \mathrm{~nm}$. Purity of RNA was assured by examining the absorbance ratio of OD260/OD280 using Biophotometer (Eppendorf Instrument, USA). For cDNA preparation, $2 \mu \mathrm{g}$ of RNA was reverse transcribed using the High-Capacity cDNA Reverse Transcription Kit (Applied Biosystems, Foster City, CA), according to the manufacturer protocol. The cDNA samples were stored at $-20^{\circ} \mathrm{C}$ until analysis. Primer specific for the genes (sequences given in Table 1) were used for PCR reactions (using Eppendorf's Master Cycler Gradient machine) with an initial denaturation at $95^{\circ} \mathrm{C}$ for $5 \mathrm{~min}$, followed by denaturation at $95^{\circ} \mathrm{C}$ for $30 \mathrm{~s}$, annealing (respective temperatures are given in Table 1) for $45 \mathrm{~s}$ and extension of $72^{\circ} \mathrm{C}$ for $1 \mathrm{~min}$ for 35 cycles for each gene (Table 1). This was followed by a final extension step at $72^{\circ} \mathrm{C}$ for $10 \mathrm{~min}$. At first, the number of cycles was optimized in the control group of animals for all gene primer set individually. PCR products were separated on agarose gel, visualized by ethidium bromide (adding $3 \mu \mathrm{l}$ of $10 \mathrm{mg} / \mathrm{ml}$ solution for each $100 \mathrm{ml}$ of gel) staining. Respective no-RT samples for each gene were used as negative template control (data not shown). Each PCR product band was quantified for densitometry using Image $J$ software and represented graphically. 
TABLE 1 | List of primers used in this study.

\begin{tabular}{|c|c|c|c|c|c|}
\hline S. No. & Gene & Primer sequence $5^{\prime}-3^{\prime}$ & $\mathrm{T}^{\mathrm{a}}$ & bp size & GenBank/Accession. No. \\
\hline \multirow[t]{2}{*}{1} & NR2A & $\mathrm{F}=$ TCAGCCATTGCTGTCTTCGT & 57.3 & 590 & AF001423.1 \\
\hline & & $\mathrm{R}=\mathrm{AGCGCAATTCCATAGCCTGT}$ & & & \\
\hline \multirow[t]{2}{*}{2} & NR2B & $\mathrm{F}=\mathrm{CCACGCACACTGTCACCTAT}$ & 60.5 & 579 & M91562.1 \\
\hline & & R = CCTCGCTGATGTCGTACAGG & & & \\
\hline 3 & m1AChR & $\mathrm{F}=\mathrm{AGCAGGCATGTGAATGACGG}$ & 60.6 & 529 & XM_006230974.2 \\
\hline 4 & & $\mathrm{R}=\mathrm{GATCCCATTCTCCGTTGGGG}$ & & & \\
\hline \multirow[t]{2}{*}{5} & nNOS & $\mathrm{F}=\mathrm{ACTGGGAGGGGAGGGATTCC}$ & 60.0 & 321 & NM_052799.1 \\
\hline & & $\mathrm{R}=\mathrm{GTCGATCGGCTGGACTTAGG}$ & & & \\
\hline \multirow[t]{2}{*}{6} & $\beta$-actin & $\mathrm{F}=\mathrm{GCCATGTACGTAGCCATCA}$ & $57.3-60.6$ & 375 & NM_031144.3 \\
\hline & & $\mathrm{R}=\mathrm{GAACCGCTCATTGCCGATAG}$ & & & \\
\hline
\end{tabular}

F, forward primer; $R$, reverse primer; $T^{a}$, Annealing temperature; bp, base pair.

\section{Protein Concentration Measurement}

The content of protein in rat brain homogenate-hippocampus was measured by the Lowry method (Lowry et al., 1951) using bovine serum albumin as standard.

\section{Assay of Acetylcholinesterase Activity in Rat Brain Hippocampus}

Acetylcholinesterase (AChE) activity was determined according to the method of Ellman et al. (1961). Briefly, $20 \mathrm{mg}$ of rat brainhippocampus tissue was homogenized with $1.0 \mathrm{ml}$ of Potassium Phosphate buffer, $\mathrm{pH}-8.0$ in a Potter-Elvehjem homogenizer. $0.4 \mathrm{ml}$ aliquot of homogenate was added to a cuvette containing $2.6 \mathrm{ml}$ of phosphate buffer (pH-7.4) followed by the addition of $100 \mu \mathrm{l}$ of the DTNB reagent. The absorbance was measured at $412 \mathrm{~nm}$ using spectrophotometer. Twenty microliters of the acetylthiocholine iodide was added and changes in absorbance per minute was calculated. The enzyme activity expressed as $\mu \mathrm{mol}$ of substrate hydrolyzed/minute/mg protein.

\section{Measurement of Hippocampal Nitrite Levels}

Nitrite determination in the biological material is increasingly being used as a marker for nitric oxide (NO) production. Nitrite levels were quantified by the protocol described by Green et al. (1982). Briefly, nitrite concentration in $100 \mu \mathrm{l}$ of supernatant was measured by using a colorimetric reaction generated by $1.0 \mathrm{ml}$ of Griess reagent (0.1\% N-(1-naphthyl) ethylenediamine dihydrochloride and $1.0 \%$ sulfanilamide in $2.5 \%$ ortho-phosphoric acid). After $10 \mathrm{~min}$ of incubation at room temperature, the absorbance at $540 \mathrm{~nm}$ was determined and nitrite concentrations were calculated from the sodium nitrite standard curve. Results are expressed in the form of $\mathrm{nmol} / \mathrm{mg}$ protein.

\section{Measurement of Hippocampal Glutathione Peroxidase Activity}

Glutathione peroxidase destroys hydrogen peroxide with the help of reduced glutathione forming water and oxidized glutathione.
The activity of glutathione peroxidase was assayed by the method of Rotruck et al. (1973). The reaction mixture consisting of $0.2 \mathrm{ml}$ each of EDTA, sodium azide and reduced glutathione $(80 \mu \mathrm{M}), 0.4 \mathrm{ml}$ of phosphate buffer, $0.7 \mathrm{ml}$ of distilled water in two set of tubes, $0.1 \mathrm{ml}$ rat brain-hippocampus homogenate was added to second tube and the tubes are incubated at $37^{\circ} \mathrm{C}$ for $5 \mathrm{~min}$. Then $0.2 \mathrm{ml}$ of hydrogen peroxide $(25 \mathrm{mM})$ and $1.0 \mathrm{ml}$ of $10 \%$ TCA is added to the first tube immediately and followed by the addition of $0.1 \mathrm{ml}$ of tissue homogenate at 0 min. One microliter of 10\% TCA is added to the second tube, $1 \mathrm{~min}$ after the addition of hydrogen peroxide, considered as 1 min. First and second set of tubes are considered as " 0 " min and "1" min reaction tube. The reaction mixture was centrifuged at $2500 \mathrm{rpm}$. From this, $2.0 \mathrm{ml}$ of supernatant, $3.0 \mathrm{ml}$ of disodium hydrogen phosphate $(300 \mathrm{mM})$ and $1.0 \mathrm{ml}$ of DTNB were added and the color developed was read at $420 \mathrm{~nm}$ and concentration of glutathione was calculated from the glutathione standard curve. The activity of GPX was expressed as $\mu \mathrm{g}$ of glutathione consumed/minute/mg protein.

\section{Measurement of Reduced Glutathione in Rat Brain Hippocampus}

Reduced glutathione in the rat brain-hippocampus was estimated according to the method described by Ellman (1959). $0.5 \mathrm{ml}$ of hippocampal homogenate was precipitated with $0.5 \mathrm{ml}$ of $4 \%$ sulfosalicylic acid and cold-digested at $4^{\circ} \mathrm{C}$ for $1 \mathrm{~h}$. The tubes were centrifuged at $1200 \mathrm{~g}$ for $15 \mathrm{~min}$ at $4^{\circ} \mathrm{C} .0 .5 \mathrm{ml}$ of supernatant, $2.7 \mathrm{ml}$ of phosphate buffer $(0.1 \mathrm{M}, \mathrm{pH}-8.0)$ and $2.0 \mathrm{ml}$ of DTNB were added. The yellow color developed was read at $412 \mathrm{~nm}$ and glutathione concentration was calculated from the glutathione standard curve. Results were expressed as $\mu \mathrm{g}$ of reduced glutathione/mg protein.

\section{Determination of Protein Carbonyl Content in Hippocampus of Rat Brain}

Two $1 \mathrm{mg}$ of protein aliquots are needed for each sample to be assayed. Samples are extracted at a final concentration of $10 \%(\mathrm{w} / \mathrm{v}) \mathrm{TCA}$. The precipitates are treated with $500 \mu \mathrm{L}$ of 
$0.2 \% \mathrm{DNPH}$ or $500 \mu \mathrm{L}$ of $2 \mathrm{~N} \mathrm{HCl}$. Samples are incubated at room temperature for $1 \mathrm{~h}$ with vortexing at 5 -min intervals. The proteins are then precipitated by adding $55 \mu \mathrm{L}$ of $100 \%$ TCA. The pellets are centrifuged and washed three times with $500 \mu \mathrm{L}$ of the ethanol:ethyl acetate mixture. The pellet is then dissolved in $600 \mu \mathrm{L}$ of $6 \mathrm{M}$ guanidine hydrochloride. The carbonyl content is determined by reading the absorbance at the optimum wavelength $(\lambda=360-390 \mathrm{~nm})$ of each sample against its appropriate blank. 2,4-dinitrophenylhydrazone protein adducts are calculated using the millimolar adsorptivity of $22.0 \mathrm{mM}^{-1}$ $\mathrm{cm}^{-1}$ for aliphatic hydrazones. Results are reported as nmol of DNPH incorporated per mg protein (Levine et al., 1994).

\section{Determination of Hippocampal Malondialdehyde Levels}

In this study, we performed malondialdehyde (MDA) assay to evaluate the level of lipid peroxidation in hippocampus of control and experimental animals. The content of MDA was determined by a modified procedure of Li et al. (2010). Each hippocampus section $(10 \mathrm{mg}$ ) was homogenized in $0.1 \mathrm{ml}$ of $10 \mathrm{mM}$ phosphate buffer ( $\mathrm{pH}$ 7.4). After centrifugation at $12,000 \mathrm{~g}$ for $20 \mathrm{~min}$, the MDA content in the supernatant was assayed by the thiobarbituric acid (TBA) reaction, and the resultant colored product was measured at $535 \mathrm{~nm}$ with spectrometer. The levels of TBA reactive species were expressed as $\mathrm{mmol} / \mathrm{mg}$ protein. Extinction coefficient for TBARS: $1.56 \times 10^{5} \mathrm{M}^{-1} \mathrm{~cm}^{-1}$.

\section{Statistical Analysis}

All statistical analysis was performed using GraphPad Prism software (Version 5.0). The data were represented as mean \pm SEM. Group comparison was performed using one-way ANOVA, followed by Tukey's multiple comparison tests. The criterion for statistical significance was $P<0.05$ in all statistical evaluations; ns, non-significant.

\section{RESULTS}

\section{Resveratrol Regulates NMDAR - NR2A and NR2B mRNA Expression in IBO Induced}

\section{Rats}

NMDAR-mediated $\mathrm{Ca}^{2+}$ influx into the postsynaptic cell triggers signal transduction cascades that control activity-dependent synaptic plasticity and neuronal survival (Sheng and Kim, 2002). NR2A and 2B containing NMDARs are required for both LTP and LTD, respectively. While activation of NMDARs is essential for long-lasting, activity-dependent synaptic plasticity, and involved in learning and memory (Wittmann et al., 2004). Hence, we intend to study the opposing function of NR2A and NR2B of NMDARs in hippocampus of control and experimental animals for which, we examined the relative gene expression of the NMDA receptors by semi-quantitative PCR analysis. The results depicted a significant $(P<0.01)$ down-regulation of NR2A and up-regulation of NR2B mRNA levels in IBO induced groups when compared to control groups (Figures 2A,B). Interestingly, these alteration of NR2A/NR2B mRNA levels induced by IBO was partially reversed by RSV treatment $(P<$ 0.05). However, no significant changes were observed between RSV alone treated groups and respective controls (group I and VI).

\section{Resveratrol Ameliorates Morphologic Abnormalities during IBO Induced Neurodegeneration in Rat Brain}

Histologic analysis of hippocampus and entorhinal cortex in the control and experimental groups of rat brain is shown in Figures 3A,B. H \& E results showed normal cellular architecture with intact cell membrane in hippocampal (Cornu ammonisCA1, CA2, CA3, CA4, and dentate gyrus) region of control and sham control rat brain. Whereas IBO induced rat showed
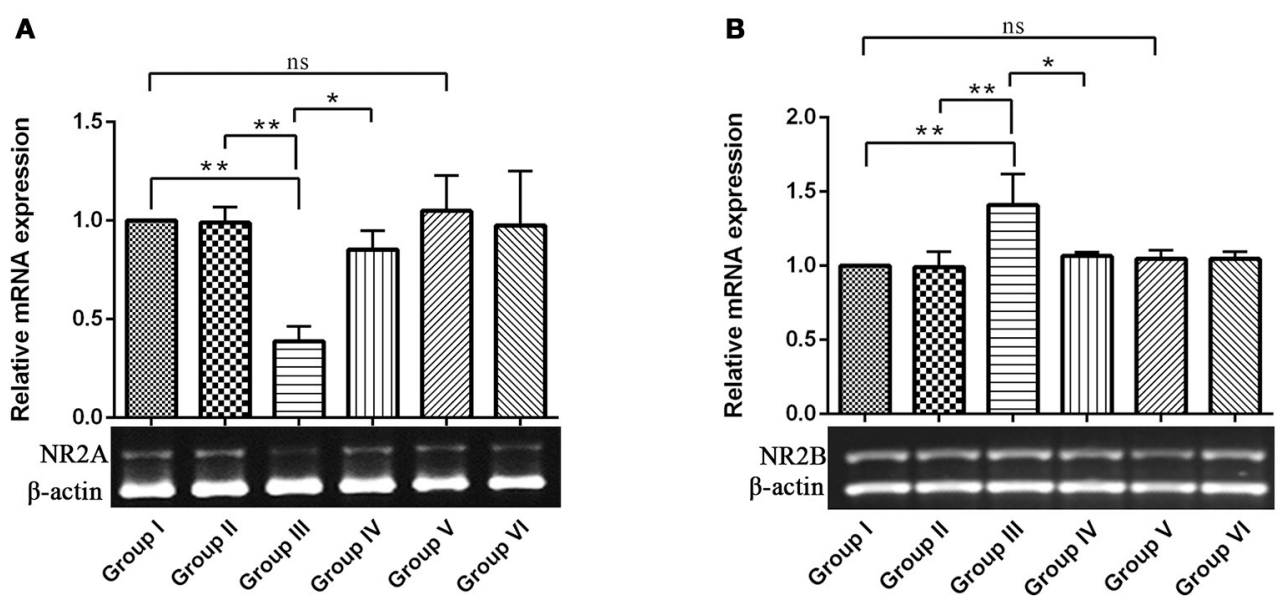

FIGURE 2 | mRNA expression of NMDA receptors (NR2A and NR2B) in control and experimental animals. NMDARs expression levels were evaluated through semi-quantitative RT (reverse transcriptase)-PCR. (A,B), Shows NR2A and NR2B mRNA expression in hippocampus of control and experimental animals with corresponding bar diagram that denotes relative mRNA expression levels which is normalized with $\beta$-actin. Values are represented as mean \pm SEM ( $n=3$ ). Statistical significance was performed by one-way ANOVA followed by Tukey's multiple comparison test. Values are statistically significant at * $P<0.05$; ${ }^{\star *} P<0.01$; ns. 


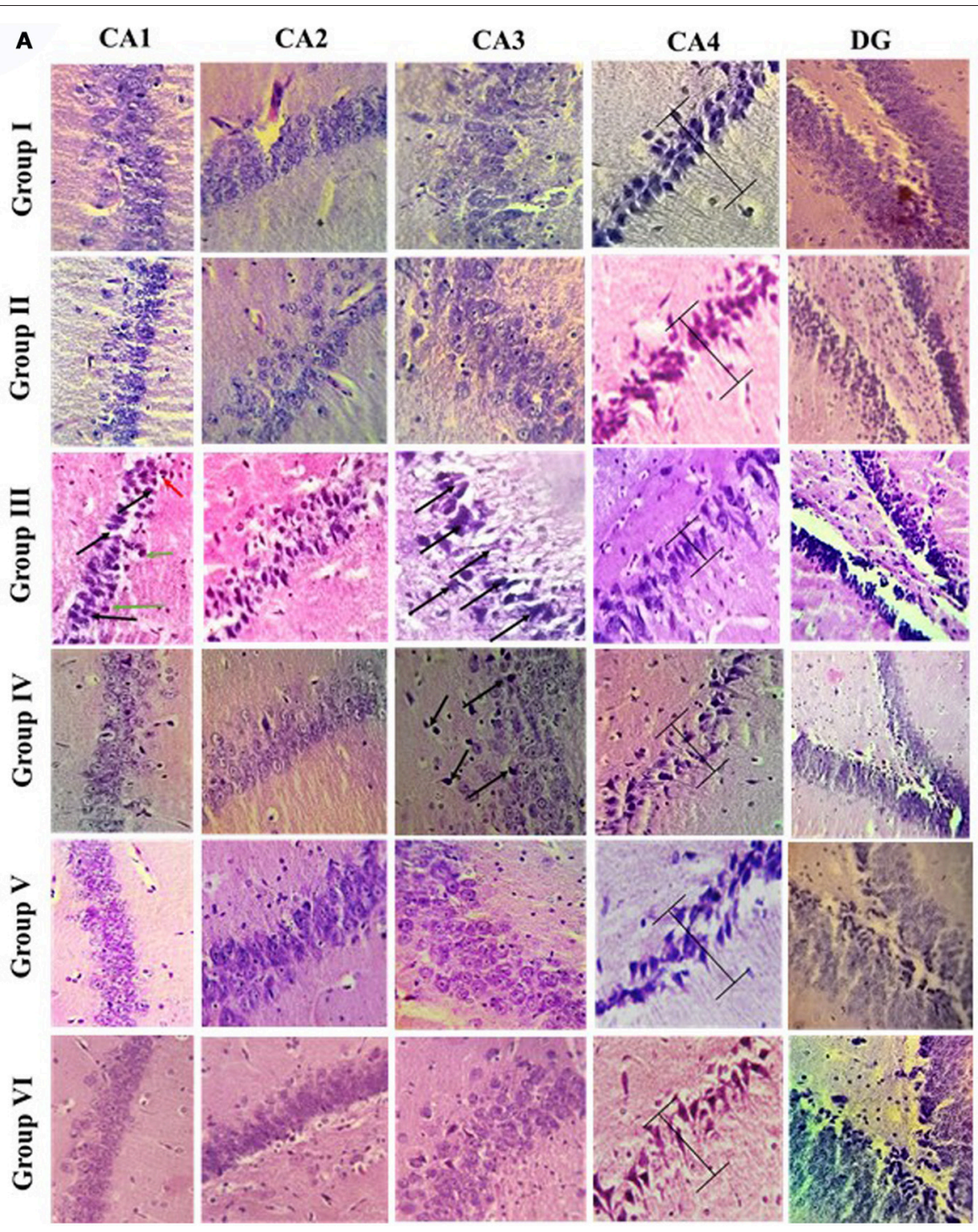

B

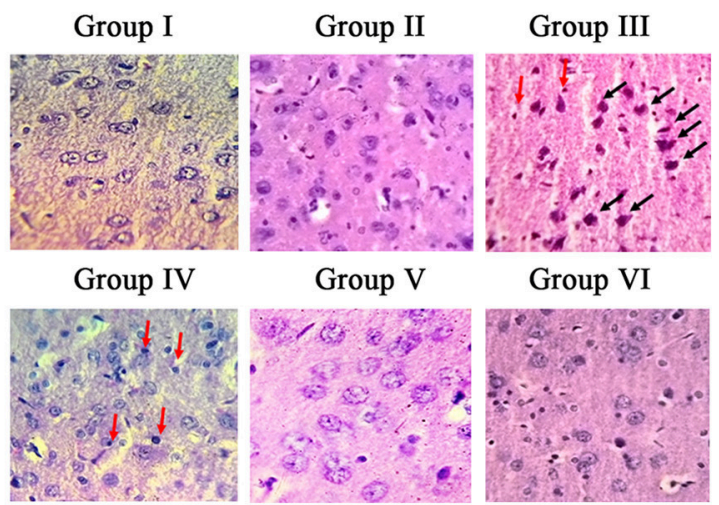

FIGURE 3 | Histopathological analysis of control and experimental group of rat brain regions: Photomicrographs showing the effect of RSV on IBO induced in vivo toxicity in hippocampus of rats (A). Sections were obtained from rat hippocampus 15 days after injection of IBO ( $n=3$ ). The morphology of the hippocampus and sub-regions are examined using $\mathrm{H}$ \& E staining. In the IBO-model group, neuron arrangement is disrupted, severe lesions such as neuronal cell loss (black arrow), pycnotic cells (green arrow), and dead cells (red arrow) are observed in the nucleus and cytoplasm. Further prevention of degeneration through neuronal loss was attempted through RSV administration (A, magnification 40X). CA1, cornus ammonis 1; CA2, cornus ammonis 2; CA3, cornus ammonis 3; CA4, cornus ammonis 4; DG, Dentate gyrus. $\mathrm{H}$ and $\mathrm{E}$ staining of hippocampus associated region like entorhinal cortex (B) is examined for the presence of apoptotic cells, degeneration pattern etc., identifying IBO mediated pathology in associated regions from site of induction (magnification 40X). 
pathological alterations such as disorganized architecture, neuronal cell loss, and dead cells in the CA1 and CA3 region of hippocampus. In addition, pyramidal layer thickness (CA4) was reduced and cell shrinkage (CA2) were seen in IBOinduced groups when compared with control groups. Further, we intend to investigate the effect of IBO induced toxicity on the associated regions of hippocampus like entorhinal cortex and amygdala. $\mathrm{H}$ \& $\mathrm{E}$ staining results exhibited pathological changes in entorhinal cortex (Figure 3B), whereas slight morphological abnormalities was observed in amygdala region (Supplementary data, Figure S2) of IBO induced group when compared with control and sham-control groups. Interestingly, RSV treated groups showed reduction in number of damaged cells and increased the number of intact neuronal cells in hippocampus and entorhinal cortex when compared to IBO-induced groups (Figure 3A). However, no specific abnormalities were observed between RSV alone treated groups and respective controls (group I and VI).

\section{Neuroprotective Effect of RSV on Mitigating Acetylcholine Receptor Gene Expression and Acetylcholinesterase Activity in IBO-Induced Rats \\ Resveratrol Regulates Cholinergic Gene Expression of Experimental and Control Animals}

To explore the mechanisms underlying the protective effects of RSV against IBO-induced cholinergic dysfunction, we examined mRNA expression of ionotrophic receptor $(\alpha 7-n A C h R, \alpha 7-$ nicotinic acetylcholine receptor) and metabotrophic receptor ( $\mathrm{m} 1 \mathrm{AChR}$, muscarinic acetylcholine receptor 1 ) in hippocampus of control and experimental animals. In Figures $4 \mathbf{A}, \mathbf{B}$, results showed that IBO-induced group exhibited significant $(P<0.01)$ down-regulation of $\alpha 7-n A C h R$ and up-regulation of m1AChR
mRNA levels by $p<0.001$ when compared to control groups. In RSV-treated groups, the expression of acetylcholine receptor, $\alpha 7$-nAChR and m1 AChR levels were significantly $(P<0.05)$ brought back when compared to IBO-induced groups. No significant difference was observed in the acetylcholine receptor gene expression between RSV alone treated groups and respective controls (group I and VI).

\section{Acetyl Cholinesterase Activity}

The cholinergic pathway is well-known for its role in learning and memory in the mammalian limbic system. Acetyl cholinesterase (AChE) is a key enzyme involved in cholinergic neurotransmission. Reductions in cholinergic function occurring early are well-correlated with the degree of cognitive impairments in patients with $\mathrm{AD}$. In the present study, the effect of RSV on the level of neurotransmitter AChE in hippocampus of experimental groups were assessed. The enzymatic activity of AChE was significantly increased $(P<$ $0.01)$ in the IBO-induced groups when compared with controls (Figure 5). The observed increase in the level of AChE was moderately reduced upon treatment with $\operatorname{RSV}(P<0.05)$. However, no significant difference in the levels of AChE activity in RSV alone treated group and respective controls (group I and VI) were observed.

\section{Behavioral Observations Resveratrol Enhances Behavioral Performance during IBO Induced Rats}

Since, IBO is a powerful excitatory neurotoxicant that may lead to the cholinergic dysfunction and memory impairments, we determined whether RSV influences positive effect on IBO induced memory defect in rats. For this, we evaluated spatial learning and memory by assessing latency period (Secs) and \%
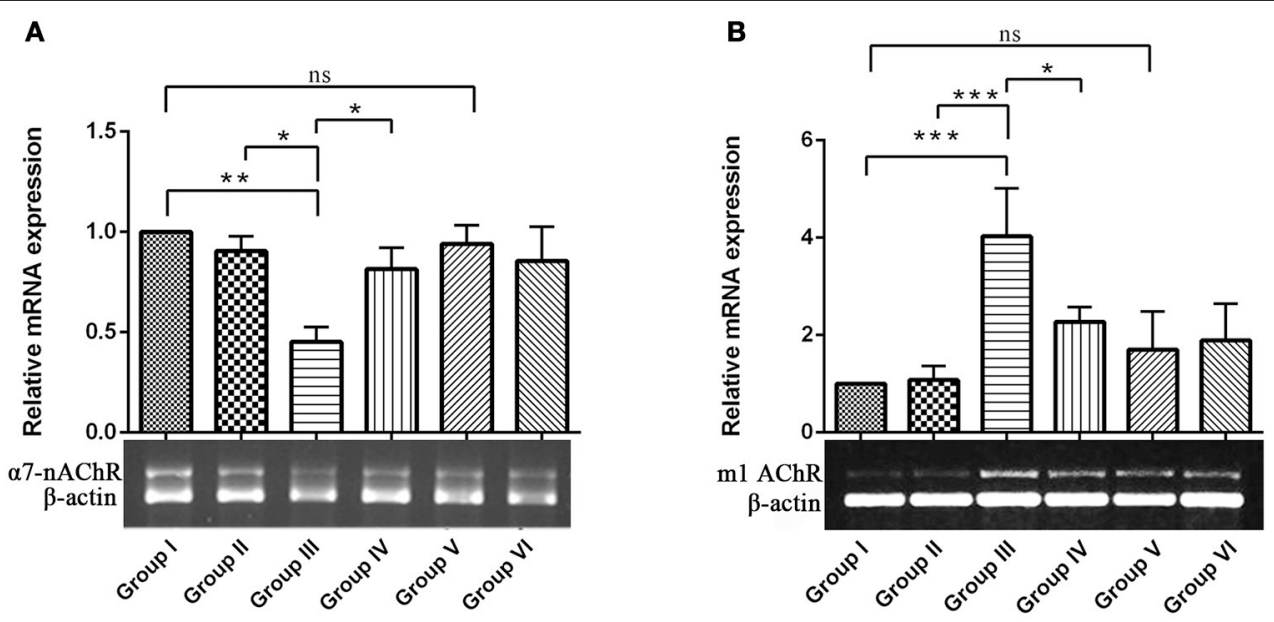

FIGURE 4 | Effects of RSV on relative mRNA expression of $\alpha 7$-nicotinic acetylcholine receptors and Muscarinic acetylcholine receptors 1 in IBO-induced hippocampus of rats. (A,B) Shows $\alpha 7-n A C h R$ and m1AChR mRNA expression in the hippocampus of control and experimental animals with corresponding bar diagram that denotes relative mRNA expression levels which are normalized with $\beta$-actin. Values are represented as mean \pm SEM $(n=3)$. Statistical significance was performed by one-way ANOVA followed by Tukey's multiple comparison test. Values are statistically significant at ${ }^{\star} P<0.05 ;{ }^{* *} P<0.01$; ${ }^{\star * \star} P<0.001 ;$ ns. 
correct response in 8-Arm RAM task after 15 days of treatment in experimental groups. The correct choices out of four daily trials, IBO induced groups displayed a decrease of $45 \%$, and the latency period was increased to about $240 \mathrm{~s}$ when compared to control groups. This shows a significant $(P<0.001)$ impairment in hippocampal lesioned rats in way of making correct choices (both working and reference memory error). Treatment with RSV for 15 days significantly $(P<0.05)$ improved RAM

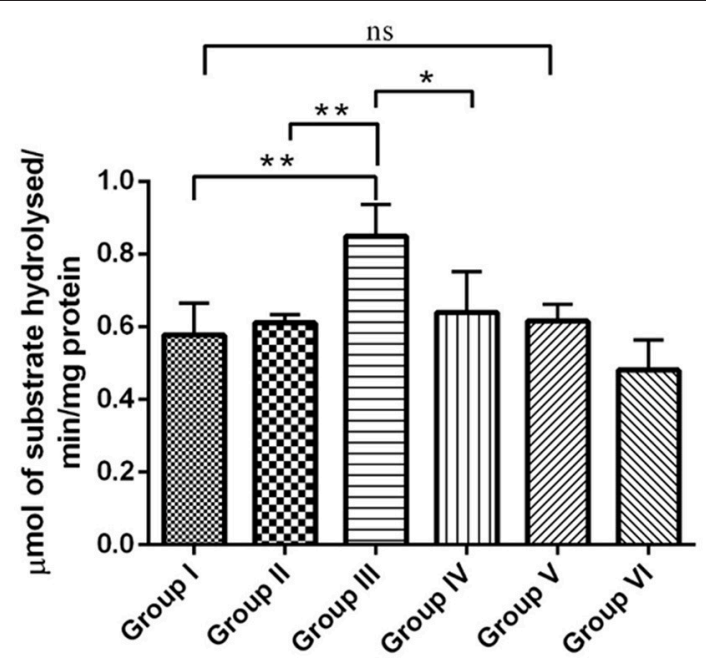

FIGURE 5 | RSV mitigates AChE activity on IBO-induced cholinergic impairments in rats. Acetylcholinesterase activity expressed as $\mu$ mols of substrate hydrolyzed/min/mg protein in the hippocampus of control and experimental animals. Values are represented as mean $\pm \operatorname{SEM}(n=4)$. Statistical significance was performed by one-way ANOVA followed by Tukey's multiple comparison test. Values are statistically significant at ${ }^{\star} P<0.05$; ${ }^{* *} P<$ $0.01 ; \mathrm{ns}$. performance thereby preventing spatial learning and memory defects, specifically the number of correct choices was $64.5 \%$ and the latency period was by $180-210 \mathrm{~s}$ was observed. There was no significant difference between RSV alone treated groups compared to respective controls (group I and VI) as shown in Figures 6A,B.

\section{Open Field Activity}

The open field test is conventionally designed to assess the state of anxiety, locomotor and exploratory activity. In comparison with the control groups, the IBO induced group showed increased propensity toward being immobile $(164.3 \pm 11.38, P<0.001)$ and decreased number of ambulation's (51.71 $\pm 1.692, P<$ $0.001)$. When IBO induced rats treated with RSV exhibited period of immobility with a value of $135.5 \pm 8.185$ that depicts a corresponding decrease and significantly increased number of ambulation's $(63.92 \pm 4.516)$ when compared to that of IBO induced group $(P<0.01)$. The decreased immobility of rats in the open-field is a characteristic pattern indicating reduced anxiety, while IBO induced rats shown more head dipping compared to RSV treated group (data not shown). There was no significant difference in RSV alone treated group and respective control groups (Figures 7A,B).

\section{RSV Reversed IBO-Induced nNOS Expression and Nitrite Production in the Hippocampus of Rat Brain}

Present study assessed the levels of nNOS mRNA expression and accumulation of nitrites in the hippocampus of rat brain. nNOS mRNA expression was significantly up-regulated in the IBO induced group compared with control groups $(P<0.01)$. Interestingly, RSV treatment significantly $(P<0.05)$ normalized the nNOS expression when compared to IBO treated group
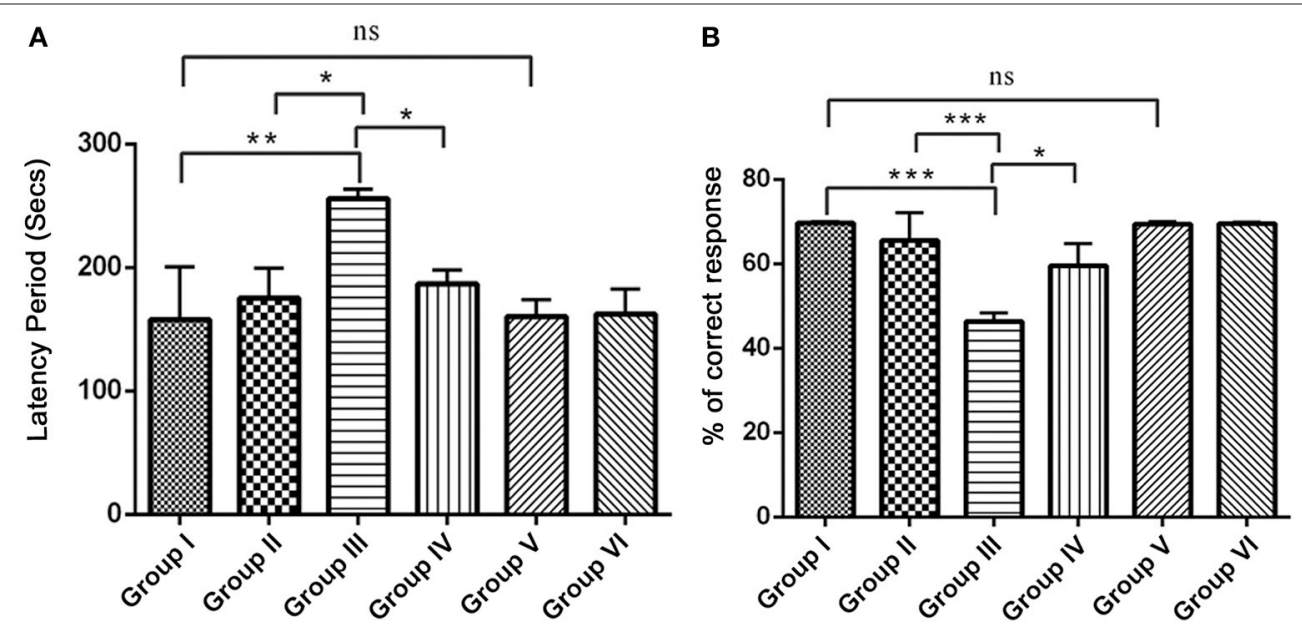

FIGURE 6 | Effect of RSV on spatial learning and memory of control and experimental rats using radial arm maze (RAM) task. The overall memory score was calculated on the basis of both training and the test phase $(n=7)$. (A) Shows the comparison of Retention time (latency period) of animals on 8-arm radial arm maze (RAM) task. The bar diagram represents the retention time of acquired task, where the retention time was assessed for 4 days following the procurement of the task. (B) Represents \% correct response as depicted by the performance of animals in 8-arm RAM baited task. The bar diagram depicts the mean percentage of correct choices made by the rats as a function of time. Each animal received five trials/day for 4 days. Values are represented as mean \pm SEM. Statistical significance was performed by one-way ANOVA followed by Tukey's multiple comparison test. Values are statistically significant at ${ }^{\star} P<0.05$; ${ }^{\star \star} P<0.01$; ${ }^{\star \star \star} P<0.001$; ns. 

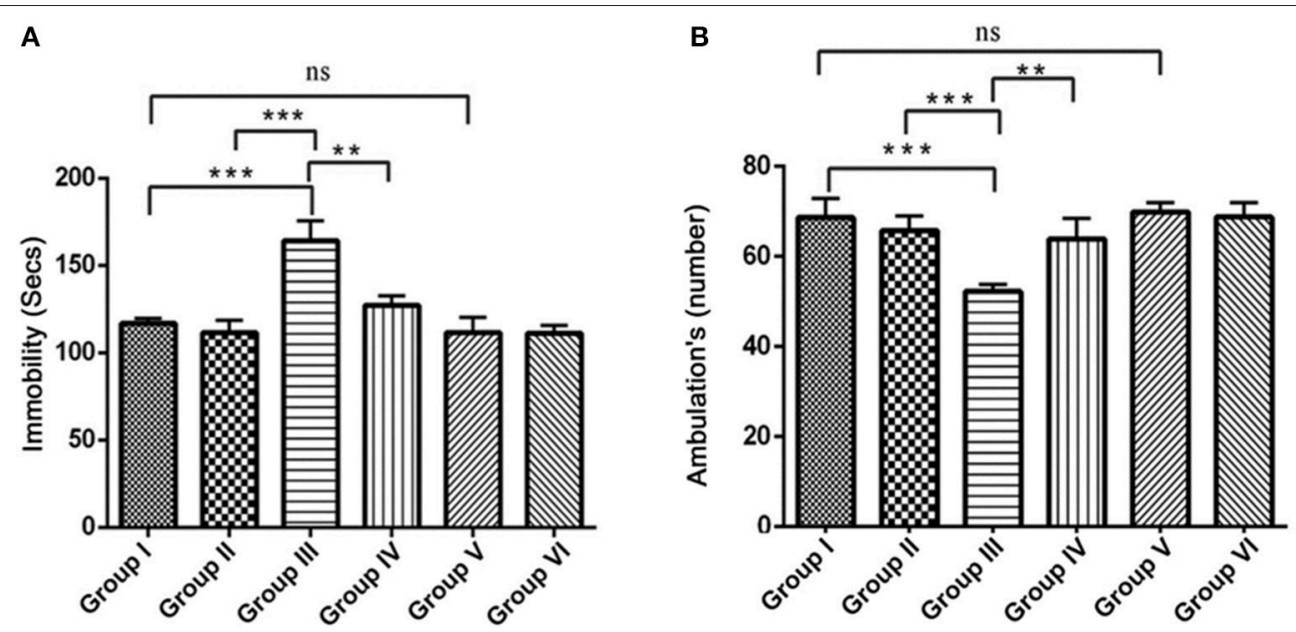

FIGURE 7 | Effect of RSV on ambulation and locomotor activity of rats assessed in the open field test for the 5 min period for two successive days. Open field test activity was measured as the number grid crossing in 5 min. (A) Depicts the period of immobility in seconds by animals in the open field maze; (B) Represents ambulatory activity of the animals in the open field task. Values are represented as mean $\pm \operatorname{SEM}(n=7)$. Statistical significance was performed by one-way ANOVA followed by Tukey's multiple comparison test. Values are statistically significant at ${ }^{\star \star} P<0.01$; ${ }^{\star * \star} P<0.001$; ns.
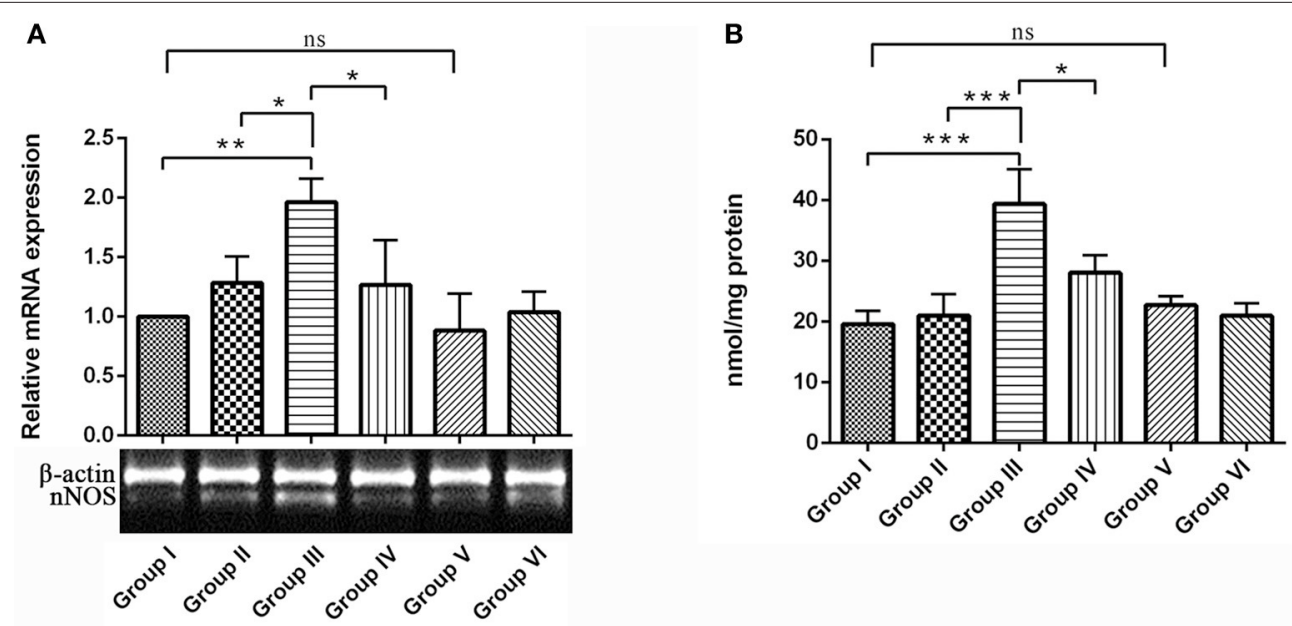

FIGURE 8 | Effect of RSV on nitrite levels and its relative mRNA expression of nNOS gene in the hippocampus of IBO lesioned rats. Panel (A) denotes $\mathrm{nNOS}$ expression levels of control and experimental animals in representative gel image with corresponding bar diagram that indicates relative mRNA expression of nNOS normalized with $\beta$-actin $(n=3)$. Panel (B) Nitrite levels expressed as nmol/mg protein in the hippocampus of control and experimental animals ( $n=4)$. Values are represented as mean \pm SEM. Statistical significance was performed by one-way ANOVA followed by Tukey's multiple comparison test. Values are statistically significant at ${ }^{\star} P<0.05 ;{ }^{* \star} P<0.01 ;{ }^{* * *} P<0.001$; ns.

(Figure 8A). In the brain, the enzyme nNOS is responsible for nitric oxide production under pathological conditions, including neurodegenerative diseases. Hence we intend to study the effect of RSV on nitrite levels in IBO induced rats. Nitrite levels were significantly increased $(P<0.001)$ in the hippocampus of IBO induced group compared to control groups. IBOinduced rats treated with RSV showed significant $(P<0.05)$ reduction in the level of nitrite compared with IBO-induced group (Figure 8B). However, no significant difference between RSV alone treated group and respective controls (group I and VI) were observed.

\section{Effect of RSV on Oxidative Parameters in the Hippocampus of IBO Induced Rats}

Figures 9A-D, shows the status of antioxidant and oxidative parameters such as GPx, GSH, PCO, and MDA levels in the hippocampus of control and experimental groups. GPx (Figure 9A) and GSH (Figure 9B) levels were significantly $(P<$ 0.001 ) reduced, whereas the levels of PCO (Figure 9C) and MDA (Figure 9D) was significantly elevated by $p<0.001$ and $p<0.01$, respectively, during IBO induction when compared to control groups. Interestingly, the adverse changes in antioxidant enzymes (GPX and GSH), PCO and MDA levels were reversed as that of 
A

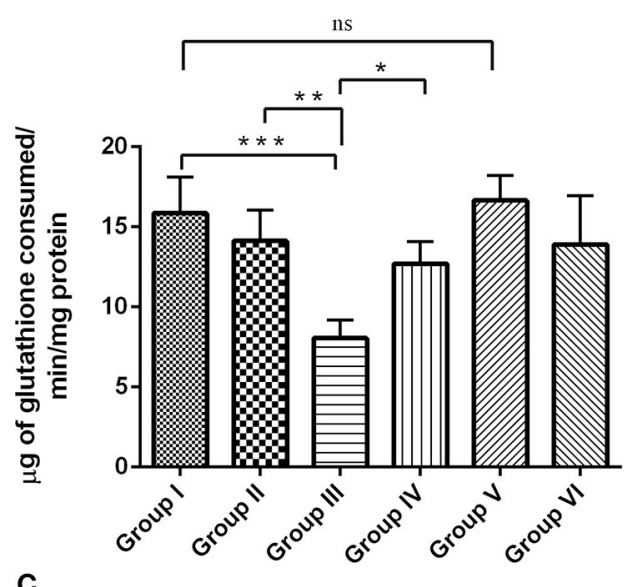

C

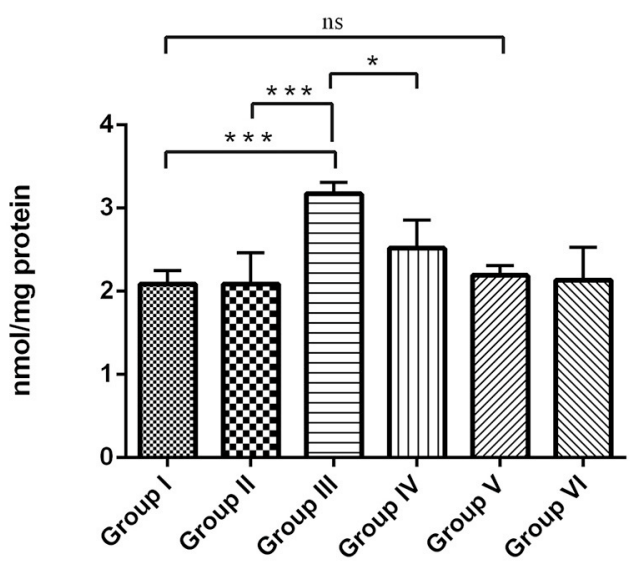

B

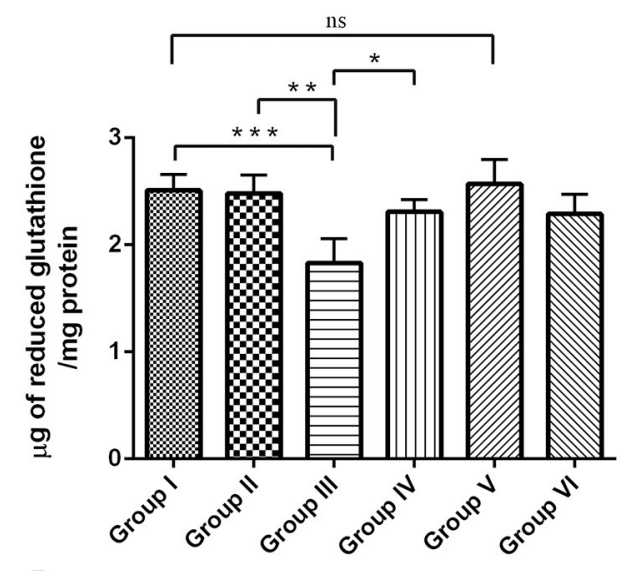

D

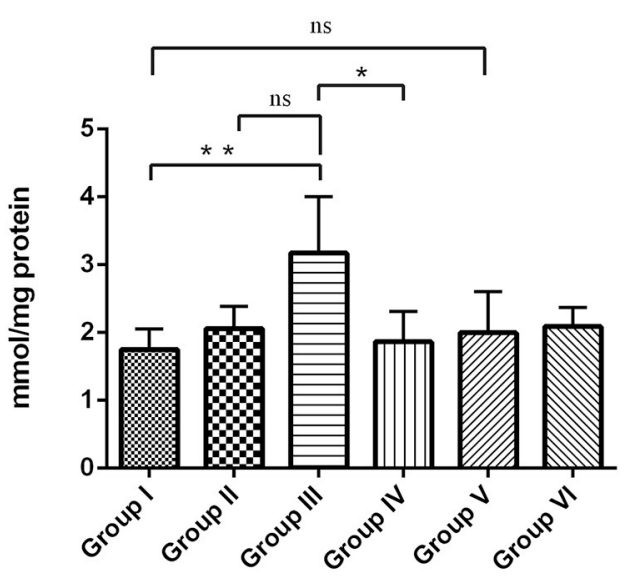

FIGURE 9 | RSV exhibits antioxidative potential by mitigating IBO-induced oxidative stress. Antioxidant efficiency of RSV on IBO induced rats was assessed by determining enzymatic antioxidants like (A) glutathione peroxidase ( $\mu \mathrm{g}$ of glutathione consumed $/ \mathrm{min} / \mathrm{mg}$ protein), (B) reduced glutathione levels ( $\mu \mathrm{g}$ of glutathione/mg protein) and its efficacy in reducing oxidative stress was determined by evaluating (C) protein carbonyl content (nmol/mg protein), and (D) malondialdehyde levels (mmol/mg protein) in the hippocampus of control and experimental rats. Rats were exposed to IBO lesions (5 $\mu \mathrm{g} / \mu \mathrm{l})$ for 15 days and effect on these parameters assessed immediately after evaluating the behavioral performance. Values are represented as mean \pm SEM $(n=4)$. Statistical significance was performed by one-way ANOVA followed by Tukey's multiple comparison test. Values are statistically significant at ${ }^{*} P<0.05 ;{ }^{* *} P<0.01 ;{ }^{* * *} P<0.001 ;$ ns.

control in RSV treated group $(P<0.05)$ when compared to IBO induced group. However, no significant difference in oxidative parameters was observed between RSV alone treated group and respective controls (group I and VI).

\section{DISCUSSION}

Evidence proved that cholinergic input to the hippocampus plays an important role in learning and memory and that degeneration of cholinergic neurons in the hippocampus may contribute to memory loss associated with neurodegenerative disease like Alzheimer's disease (AD) (Pepeu et al., 2015). Current study employs IBO, a glutamate agonist for the induction of excitotoxicity mediated cholinergic dysfunction in the regions of hippocampus to study the role of RSV in preventing neurodegeneration. Excitotoxicity is mediated by excessive and dysregulated activation of glutamate receptor (NMDA), where prolonged exposure to high or persistently increased concentration of glutamate/glutamate agonist can lead the cell expressing these receptors to death (Choi, 1994; Degos et al., 2013). Observation on the levels of hippocampal NR2B displayed a significant increase in the mRNA levels with decreased NR2A subunit of NMDA was evident in the current study (Figures 2A,B). These are the ligand binding domains of NMDA in the pyramidal neurons of the hippocampus where, NR2B involves in efficient calcium influx promoting synaptic plasticity (Nicolai et al., 2010). Current observation of increased NR2B over NR2A clearly implies that this metabotrophic channel expressed widely in response to IBO might allow increased $\mathrm{Ca}^{2+}$ influx, thereby mediating cell death.

In line to the above suspicion, current observation with IBO induction, mediated significant pathological changes in regions of $\mathrm{CA} 1$ and $\mathrm{CA} 3$ with increased dead cells and 
displayed disorganized arrangement of cells in hippocampus (Figure 3A). Increased $\mathrm{Ca}^{2+}$ influx through NMDA receptors could directly activate catabolic enzymes such as proteases, phospholipases, and nucleases that directly cause cell demise and tissue damage like cytoskeleton/membrane damage (Berliocchi et al., 2005). These observations well-correlate with $A \beta$ induced toxicity that are mediated by several mechanisms, like oxidative stress, alterations in membrane potential, synaptic dysfunction, excitotoxicity through its interaction with the neurotransmitter receptors (Canevari et al., 1999; Rosales-Corral et al., 2004; Parameshwaran et al., 2008). Therefore, the present study using IBO induction in hippocampal CA3 region mimics $\mathrm{AD}$ condition that could facilitate efficient drug target to these aspects of neurodegeneration.

RSV administration to IBO induced rats has efficiently brought forth normalization of receptor expression viz., NR2A/NR2B levels and significantly reduced the morphological changes in the hippocampus of experimental rats as shown in Figures 2A,B, 3A,B thereby preventing excitotoxicity mediated cell death. Cellular energy stores are depleted during excitotoxicity with a decrease in levels of ATP and nicotinamide adenine dinucleotide (NAD+). NAD+ is an important energy substrate and cofactor involved in multiple metabolic reactions (Brennan et al., 2006), including glycolysis, DNA repair processes, and the function of several NAD+dependent enzymes, such as the histone deacetylase, SIRT1 (Liu et al., 2008). Therefore, loss of SIRT1 activity is assumed to be an evident phenomenon during excitotoxicity, and thereby RSV administration expected to positively induce cellular metabolic stress response preventing energy deficits through a compensatory mechanism by activating sirtuin mediated pathways. Our previous study on RSV was found to be effective in enhancing SIRT1 levels during normal aging (Moorthi et al., 2015). Thus, it is clearly evident that RSV could have prevented further toxic effects by normalizing SIRT1.

It is noted that prolonged activation of NMDA receptor by IBO infusion might trigger enormous $\mathrm{Ca}^{2+}$ influx that could impact cholinergic neurons expressing specific ACh receptor subtypes. nAChRs, particularly $\alpha 7-n A C h R$ having one of the highest permeability to calcium ions and are regulated by cytoplasmic calcium levels, suggesting a complex reciprocal relationship (Jack and Wonnacott, 2015). Present study demonstrated that IBO induced rats reduced hippocampal mRNA expression of $\alpha 7$-nAChR that may lead to cholinergic dysfunction (Figure 4A). Levin et al. (1999) demonstrated decreased functioning of hippocampal $\alpha 7$ receptors that contribute to cognitive impairment by chronic systemic coinfusion of mecamylamine and IBO lesions.

Studies provide evidence that $(\mathrm{mAChR})$ muscarinic receptor gene product mediates the modulation of NMDAR-mediated excitatory synaptic transmission (Marino et al., 1998). Reports also suggest that activation of $\mathrm{m} 1$ muscarinic $\mathrm{ACh}$ receptor in hippocampal interneurons decreased the function of $\alpha 7$ nAChRs in a calcium-dependent manner (Shen and Yake, 2009). Surprisingly, study on m1AChR levels on IBO induced rats displayed significant increase in its mRNA expression $(P<0.001)$ as seen in RT-PCR analysis (Figure 4B). Current observations clearly evidence the strategies in response to excitotoxicity by upregulating $\mathrm{m} 1 \mathrm{AChR}$ expression with significant down regulation of nicotinic $\mathrm{ACh}$ receptors sensing $\mathrm{Ca}^{2+}$ pool inside the neuronal cells. Interestingly, RSV administration has significantly reversed the abnormalities of $\alpha 7$-nAChRs and $\mathrm{m} 1 \mathrm{AChR}$ in IBO induced rats (Figures 4A,B).

Reduced expression of $\alpha 7 \mathrm{AChR}$ during IBO induction could impact ACh levels by reducing its concentration in the synaptic cleft. Reduction in the expression of $\alpha 7-\mathrm{AChR}$ thereby questions the status of AChE activity during excitotoxicity in regulating $\mathrm{ACh}$ levels. In support of this view, it was interesting to note that $\mathrm{AChE}$ was found to be significantly increased $(P<0.01)$ in IBO induced rat hippocampus, which was brought back to near normal on administration of RSV (Figure 5). An increased AChE activity may have a significant role in the reduction of ACh level, in response to reduced $\alpha 7-\mathrm{AChR}$. While prolonged disruption of $\mathrm{ACh}$ release raise the possibility of disrupting cholinergic nerve impulse transmission and thereby might delay the transmission of signals to adjacent regions of rat brain leading to gradual neurodegeneration. It is reported that IBO-induced lesions to medial septum, at the source of hippocampal branches of the forebrain cholinergic projection system, rats showed long-lasting stable impairment in reference and working memory in both spatial (place) and in associative (cue) radial maze tasks (Hodges et al., 1991).

Consistent with the previous reports, the present study demonstrated that the injection of IBO produced significant memory impairment due to disturbed synaptic plasticity and loss of spatial working memory (Figures 6A,B) that might be due to alterations in cholinergic markers as indicated by increased AChE activity reducing ACh in hippocampus. It has also been reported that modulation in NR2A gene may produce viable cells with impaired plasticity (Rolf et al., 1998) and is in line with the current observations. Current study displayed significant reduction in memory performance and locomotor activity indicating impairment in either of the excitation nerve impulse transmission modes.

Learning and memory are complex processes involving several brain regions and neuronal networks, where the hippocampus and its associated region play a critical role in generating cognitive maps. Reference memory is trial independent that is relevant for spatial cue locations while working memory is trial dependent one (Luine et al., 1998). Here, we used RAM task to assess spatial as well as working memory performance that helps study the cognitive behavior of IBO induced rats. However, during Trial 1 , there was no significant difference in the response among groups, suggesting that all rats began each session of learning and memory task at a similar level. During subsequent trials, there was a significant difference $(P$ $<0.001$, Figure 6B) in lesioned rats, indicating the defects in the learning memory. We found that post-training of rats after IBO lesion seems to be more disruptive when compared to rat's performance before IBO induction (data not shown). This was suggested due to problems in the glutamatergic neurons leading to a deficits in place memory and episodic memory as well (Viskontas et al., 2000; Neves et al., 2008). RSV treated rats performed with an increased percent of correct response 
when compared to control groups (Figure 6B). Research reports provided evidence that RSV improved impaired learning and memory in neurodegenerative disease like $\mathrm{AD}, \mathrm{HD}$ models or cognitive impairment induced by Scopolamine, Prenatal stress and Kainic acid (Gacar et al., 2011; Pushpalatha et al., 2013; Sahu et al., 2013).

Open field activity may be sensitive to hippocampal CA3 and mossy fiber pathways (Lim et al., 2001) and therefore increased open field activity has been used as an index of locomotor, anxiety and exploratory activity in IBO induced rats (Figure 7A). Significant reductions in open field activity were observed in RSV treated rats $(P<0.01)$, indicating better locomotor and exploratory activity, as shown in Figure 7A. As observed earlier, the present study showed that RSV normalized the expression of both $\alpha 7-n A C h R$ and m1AChR mRNA expression which could have further reduced the complication of motor behavior as evidenced in the open field activity assessment. To further examine anxiety of IBO induced animals, other behavioral parameters were assessed including rearing, grooming, and head dipping. IBO induced animals engaged in more head dipping (Figure 7B) as ambulatory response, but there were no differences in rearing and grooming (data not shown). It is indeed reported that NR2A KO mice exhibit deficits in learning and memory performance and certain forms of synaptic plasticity, along with hypersensitivity to behavioral effects of antipsychotics (Kishimoto et al., 2001). RSV administration has been significantly reduced the behavioral abnormalities (Figure 7B) to a significance of $p<0.01$.

IBO found to exhibit excitotoxicity either by oxidative stressmediated cell death or as source-specific that might be the consequential event of calcium influx through NMDA receptor, where source specificity is reported to exhibit toxicity through nNOS activity increasing the production of nitric oxide levels inducing cell death (Di Biase et al., 2008; Soriano et al.,
2008). The present study using IBO mediated excitotoxicity on NMDA receptors reflected an increase in nNOS expression that simultaneously increased nitric oxide levels as evidenced by measurement of nitrites (Figures 8A,B). Evidence suggests that impaired cholinergic signaling is a consequence of neuronal vulnerability to free radicals like nitric oxide mediated nitrites in vivo (Mattson, 1998). Moreover, nitric oxide is reported to alter ACh release (Guevara-Guzman et al., 1994) disrupting cholinergic transmission. This supported our findings on the increased activity of $\mathrm{AChE}$ in response to $\alpha 7-\mathrm{nAChR}$ expression, providing the strategies developed by cholinergic neurons during excitotoxicity. RSV exhibited a rescue effect decreasing AChE activity rejuvenating synaptic junctions of cholinergic neurons through its antioxidant activity. Further, reduction in nNOS and nitrite levels in IBO induced rats by RSV might have imparted a positive influence in reverting cholinergic abnormalities.

Antioxidant property of RSV was well-proved in the current observation, where RSV could normalize antioxidants like GPX activity (Figure 9A), GSH (Figure 9B) simultaneously reducing the levels of macromolecular damage decreasing protein carbonylation (Figure 9C), and Lipid peroxidation (Figure 9D). Glutathione (GSH) can serve as a neuromodulator/neurotransmitter that binds to NMDA receptors via its $\gamma$-glutamyl moiety (Janáky et al., 1999) and is thought to exert dual action as an agonist and antagonist on neuronal responses mediated by NMDA receptors in the brain (Aoyama et al., 2011). GSH is required for cell proliferation and neuronal differentiation (Poot et al., 1995). The observed reduction in GSH levels on IBO induced rat hippocampus indicates the rate of increase in oxidative stress. Oxidative stress is the major factor implicated in the pathogenesis of $\mathrm{AD}$. GSH works as an electron donor for the reduction of $\mathrm{H}_{2} \mathrm{O}_{2}$ or other peroxidases catalyzed by GPx. The GPx levels were further studied to be significantly decreased on IBO induction.

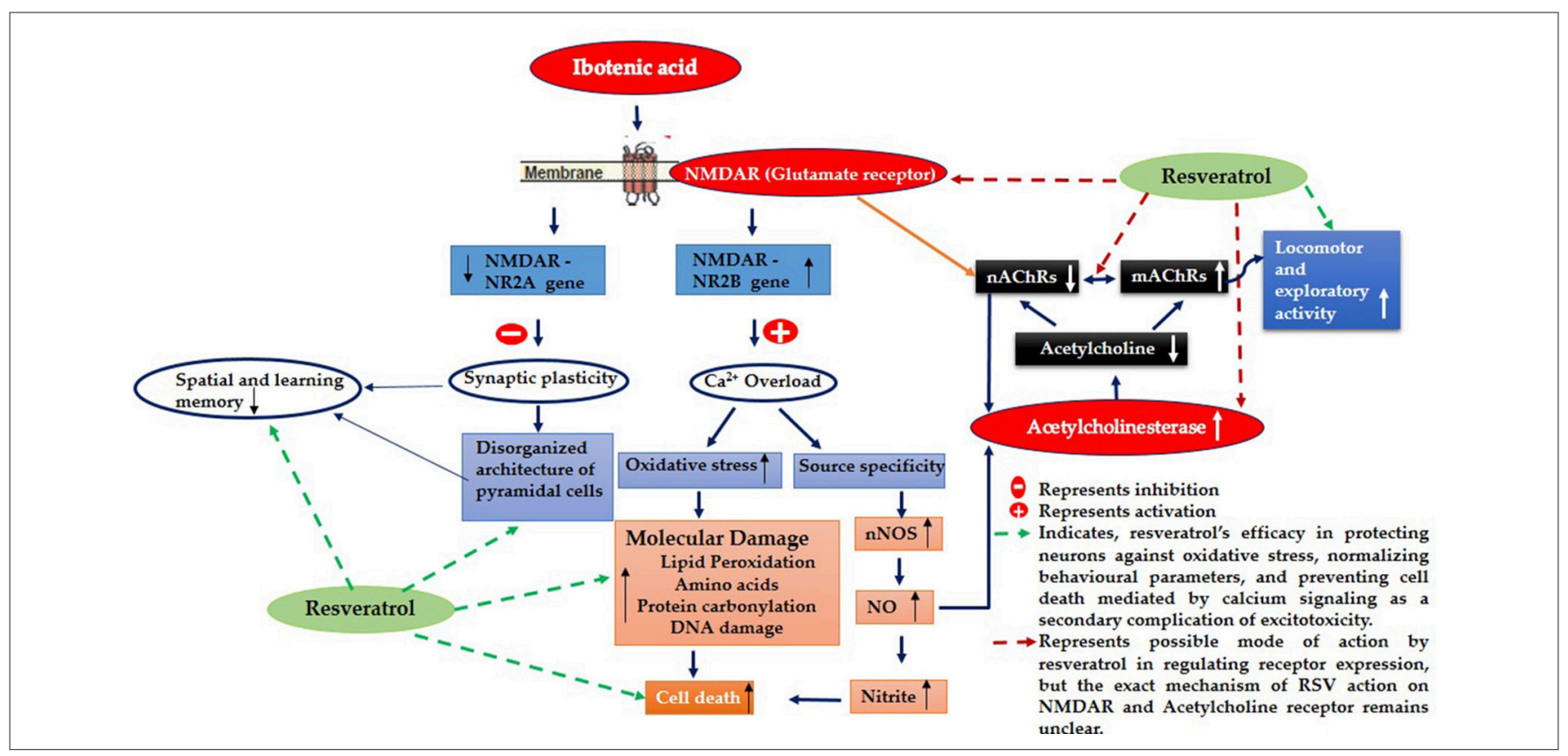


Numerous investigations have reported that RSV could directly scavenge various free radicals viz., superoxide, peroxyl, and hydroxyl radicals (Leonard et al., 2003; Bradamante et al., 2004; Schmatz et al., 2012). Our results clearly suggested that RSV administration has potentiated the increase in GPx activity and GSH levels that had rendered positive impact on reducing protein carbonylation and lipid peroxidation levels. Thus, RSV considered as an efficient drug target against IBO induced excitotoxicity preventing cell enhancing pyramidal neurons of the hippocampus and is reflected in the normal architecture of IBO induced rats.

\section{CONCLUSION}

The current study proved that IBO induction into hippocampal CA3 region mediated its toxicity through activation of NMDA subunits that negatively influenced cholinergic receptors resulting in memory impairment and defective locomotor behavior. While the mechanism behind alteration in cholinergic receptor still remains elusive. RSV exhibited protective role by normalizing the expression of glutamatergic and cholinergic receptors, maintaining homeostasis that may be due to its influence on SIRT1 in vivo as reported in our earlier studies. Further, the positive influence of RSV on IBO toxicity was evident through reduction in macromolecular damage, reduced morphological abnormalities and normal behavioral patterns proving its ability as potent neuroprotective compound. It is therefore could be considered as a promising agent to treat degenerating neuronal diseases accompanied by memory loss.

\section{REFERENCES}

Antzoulatos, E. G., and Byrne, J. H. (2004). Learning insights transmitted by glutamate. Trends Neurosci. 27, 555-560. doi: 10.1016/j.tins.2004.06.009

Aoyama, N., Théberge, J., Drost, D. J., Manchanda, R., Northcott, S., and Neufeld, R. W. J. (2011). Grey matter and social functioning correlates of glutamatergic metabolite loss in schizophrenia. Br. J. Psychiatry 198, 448-456. doi: 10.1192/bjp.bp.110.079608

Auerbach, J. M., and Segal, M. (1994). A novel cholinergic induction of long-term potentiation in rat hippocampus. J. Neurophysiol. 72, 2034-2040.

Avwioro, G., Iyiola, S., and Aghoghovwia, B. (2010). Histological and biochemical markers of the liver of Wistar rats on subchronic oral administration of green tea. North Am. J. Med. Sci. 2, 376-380. doi: 10.4297/najms.2010.2376

Berliocchi, L., Bano, D., and Nicotera, P. (2005). $\mathrm{Ca}^{2+}$ signals and death programmes in neurons. Philos. Trans. R. Soc. Lond. B. Biol. Sci. 360, 2255-2258. doi: 10.1098/rstb.2005.1765

Bradamante, S., Barenghi, L., and Villa, A. (2004). Cardiovascular protective effects of RSV. Cardiovasc. Drug Rev. 22, 169-188. doi: 10.1111/j.15273466.2004.tb00139.x

Brennan, A. M., Connor, J. A., and Shuttleworth, C. W. (2006). NAD(P)H fluorescence transients after synaptic activity in brain slices: predominant role of mitochondrial function. J. Cereb. Blood Flow Metab. 26, 1389-1406. doi: 10.1038/sj.jcbfm. 9600292

Brown, R. E., Corey, S. C., and Moore, A. K. (1999). Differences in measures of exploration and fear in MHC-congenic C57BL/6J and B6-H-2K mice. Behav. Genet. 29, 263-271. doi: 10.1023/A:1021694307672

Canevari, L., Clark, J. B., and Bates, T. E. (1999). $\beta$-Amyloid fragment 25-35 selectively decreases complex IV activity in isolatedmitochondria. FEBS Lett. 457, 131-134. doi: 10.1016/S0014-5793(99)01028-5

\section{AUTHOR CONTRIBUTIONS}

CK and MA designed the research work; CK and KJ did Stereotaxic surgery for IBO induction; CK and SP performed Biochemical analysis, Behavioral analysis, and RT-PCR studies. $\mathrm{CK}$ and MA interpreted the data, and drafted the manuscript. All authors read and approved the final manuscript.

\section{ACKNOWLEDGMENTS}

The authors gratefully acknowledge Council of Scientific and Industrial Research (CSIR) for the Senior Research Fellowship to CK (09/475 (0194) /2014-EMR-I) and Department of Biotechnology (DBT, No. 102/IFD/SAN/PR-2459/2011) New Delhi, India for the financial assistance. The infrastructure of our department is supported by the Department of Science and Technology-Fund for Improvement of S and T Infrastructure in Universities and Higher Educational Institutions (DST-FIST). We thank Dr. V. Sankar, and Dr. R. Ramesh Kumar, Department of Anatomy, IBMS, University of Madras, Chennai, India for training the stereotaxic accessories. The authors are also grateful to Dr. M. Manickavasagam, Department of Biotechnology and Genetic Engineering, Bharathidasan University, Tiruchirappalli for his help with gel documentation studies.

\section{SUPPLEMENTARY MATERIAL}

The Supplementary Material for this article can be found online at: http://journal.frontiersin.org/article/10.3389/fnmol. 2016.00028

Choi, D. W. (1994). Glutamate receptors and the induction of excitotoxic neuronal death. Prog. Brain Res. 100, 47-51. doi: 10.1016/S0079-6123(08)60767-0

Citron, M. (2010). Alzheimer's disease: strategies for disease modification. Nat. Rev. Drug Discov. 9, 387-398. doi: 10.1038/nrd2896

Clark, D., Tuor, U. I., Thompson, R., Institoris, A., Kulynych, A., Zhang, X., et al. (2012). Protection against recurrent stroke with RSV: endothelial protection. PLoS ONE 7:e47792. doi: 10.1371/journal.pone.0047792

Degos, V., Charpentier, T. L., Chhor, V., Brissaud, O., Lebon, S., Schwendimann, L., et al. (2013). Neuroprotective effects of dexmedetomidine against glutamate agonist-induced neuronal cell death are related to increased astrocyte brainderived neurotrophic factor expression. Anesthesiology 118, 1123-1132. doi: 10.1097/ALN.0b013e318286cf36

Di Biase, V., Obermair, G. J., Szabo, Z., Altier, C., Sanguesa, J., Bourinet, E., et al. (2008). Stable membrane expression of postsynaptic CaV1.2 calcium channel clusters is independent of interactions withAKAP79/150 and PDZ proteins. J. Neurosci. 28, 13845-13855. doi: 10.1523/JNEUROSCI.3213-08.2008

Ellman, G. L. (1959). Tissue sulfhydryl groups. Arch. Biochem. Biophys. 82, 70-77. doi: 10.1016/0003-9861(59)90090-6

Ellman, G. L., Courtney, K. D., Andress, V., and Featherstone, R. M. (1961). A new and rapid colorimetric determination of acetylcholine esterase activity. Biochem. Pharmacol. 7, 88-95. doi: 10.1016/0006-2952(61)90145-9

Francis, P. T. (1993). Cortical pyramidal neuron loss may cause glutamatergic hypoactivity and cognitive impairment in Alzheimer's disease: investigative and therapeutic perspectives. J. Neurochem. 60, 1589-1604. doi: 10.1111/j.14714159.1993.tb13381.x

Francis, P. T., Parsons, C. G., and Jones, R. W. (2012). Rationale for combining glutamatergic and cholinergic approaches in the symptomatic treatment of Alzheimer's disease. Expert Rev. Neurother. 12, 13511365. doi: 10.1586/ern.12.124 
Gacar, N., Mutlu, O., Utkan, T., Celikyurt, I. K., Gocmez, S. S., and Ulak, G. (2011). Beneficial effects of RSV on scopolamine but not mecamylamine induced memory impairment in the passive avoidance and Morris water maze tests in rats. Pharmacol. Biochem. Behav. 99, 316-323. doi: 10.1016/j.pbb.2011.0 5.017

Gong, B., Vitolo, O. V., Trinchese, F., Liu, S., Shelanski, M., and Arancio, O. (2004). Persistent improvement in synaptic and cognitive functions in an Alzheimer mouse model after rolipram treatment. J. Clin. Invest. 114, 1624-1634. doi: $10.1172 /$ JCI22831

Green, L. C., Wagner, D. A., Godowsky, J., Skipper, P. L., Wishnok, J. S., and Tannenbaum, S. R. (1982). Analysis of nitrate, nitrite and [15N] nitrate in biological fluids. Anal. Biochem. 126, 131-138. doi: 10.1016/00032697(82)90118-X

Guevara-Guzman, R., Emson, P. C., and Kedrick, K. M. (1994). Modulation of in vivo striatal transmitter release by nitric oxide and cyclic GMP. J. Neurochem. 62, 807-810. doi: 10.1046/j.1471-4159.1994.62020807.x

Hodges, H., Allen, Y., Kershaw, T., Lantos, P. L., Gray, J. A., and Sinden, J. (1991). Effects of cholinergic-rich neural grafts on radial maze performance of rats after excitotoxic lesions of the forebrain cholinergic projection system-I. Amelioration of cognitive deficits by transplants into cortex and hippocampus but not into basal forebrain. Neuroscience 45, 587-607. doi: 10.1016/03064522(91)90273-Q

Jack, L., and Wonnacott, S. (2015). Sazetidine-A activates and desensitizes native $\alpha 7$ nicotinic acetylcholine receptors. Neurochem. Res. 40, 2047-2054. doi: 10.1007/s11064-014-1302-6

Janáky, R., Ogita, K., Pasqualotto, B. A., Bains, J. S., Oja, S. S., Yoneda, Y., et al. (1999). Glutathione and signal transduction in the mammalian CNS. J. Neurochem. 73, 889-902. doi: 10.1046/j.1471-4159.1999.0730889.x

Ji, C., Li, Q., Aisa, H., Yang, N., and Dong, Y., L. (2009). Gossypium herbaceam extracts attenuate IBO-induced excitotoxicity in rat hippocampus. J. Alzheimer Dis. 16, 331-339. doi: 10.3233/JAD-2009-0979

Kishimoto, Y., Kawahara, S., Mori, H., Mishina, M., and Kirino, Y. (2001). Long-trace interval eyeblink conditioning is impaired in mutant mice lacking the NMDA receptor subunit epsilon 1. Eur. J. Neurosci. 13, 1221-1227. doi: 10.1046/j.0953-816x.2001.01486.x

Leonard, S. S., Xia, C., Jiang, B. H., Stinefelt, B., Klandorf, H., Harris, G. K., et al. (2003). RSV scavenges reactive oxygen species and effects radical-induced cellular responses. Biochem. Biophys. Res. Commun. 309, 1017-1026. doi: 10.1016/j.bbrc.2003.08.105

Levin, E. D., Christopher, N. C., Weaver, T., Moore, J., and Brucato, T. (1999). Ventral hippocampal IBO lesions block chronic nicotine-induced spatial working memory improvement in rats. Cogn. Brain Res. 7, 405-410. doi: 10.1016/S0926-6410(98)00044-5

Levine, R. L., Williams, J. A ., Stadtman, E. R., and Shacter, E. (1994). Carbonyl assays for determination of oxidatively modified proteins. Methods Enzymol. 233, 346-357. doi: 10.1016/S0076-6879(94)33040-9

Li, J., Wang, C., Zhang, J. H., Cai, J. M., and Cao, Y. P. (2010). Hydrogen-rich saline improves memory function in a rat model of amyloid-beta-induced Alzheimer's disease by reduction of oxidative stress. Brain Res. 1328, 152-161. doi: 10.1016/j.brainres.2010.02.046

Lim, G. P., Yang, F., Chu, T., Gahtan, E., Ubeda, O., Beech, W., et al. (2001). Ibuprofen effects on Alzheimer pathology and open field activity in APPsw transgenic mice. Neurobiol. Aging 22, 983-991. doi: 10.1016/S01974580(01)00299-8

Liu, D., Pitta, M., and Mattson, M. P. (2008). Preventing NAD+ depletion protects neurons against excitotoxicity: bioenergetic effects of mild mitochondrial uncoupling and caloric restriction: mitochondria and oxidative stress in neurodegenerative disorders. Ann. NY Acad. Sci. 1147, 275-282. doi: 10.1196/annals.1427.028

Lowry, O. H., Rosenbrough, N. J., Farr, A. L., and Randall, R. J. (1951). Protein measurement with the Folin phenol reagent. J. Biol. Chem. 193, 351-358.

Luine, V. N., Richards, S. T., Wu, V. Y., and Beck, K. D. (1998). Estradiol enhances learning and memory in a spatial memory task and effects levels of monoaminergic neurotransmitters. Horm. Behav. 34, 149-162. doi: 10.1006/hbeh.1998.1473

Marambaud, P., Zhao, H., and Davies, P. (2005). RSV promotes clearance of Alzheimer's disease amyloid- $\beta$ peptides. J. Biol. Chem. 280, 37377-37382. doi: 10.1074/jbc.M508246200
Marino, M. J., Rouse, S. T., Levey, A. I., Potter, L. T., and Conn, P. J. (1998). Activation of the genetically defined $\mathrm{m} 1$ muscarinic receptor potentiates $\mathrm{N}$ methyl-d-aspartate (NMDA) receptor currents in hippocampal pyramidal cells. Proc. Natl. Acad. Sci. U.S.A. 95, 11465-11470. doi: 10.1073/pnas.95.19. 11465

Mattson, M. P. (1998). Modification of ion homeostasis by lipid peroxidation: roles in neuronal degeneration and adaptive plasticity. Trends Neurosci. 21, 53-57. doi: 10.1016/S0166-2236(97)01188-0

Mattson, M. P. (2004). Pathways towards and away from Alzheimer's disease. Nature 430, 631-639. doi: 10.1038/nature02621

Moorthi, P., Premkumar, P., Priyanka, R., Jayachandran, K. S., and Anusuyadevi, M. (2015). Pathological changes in hippocampal neuronal circuits underlie age-associated neurodegeneration and memory loss: positive clue toeards SAD. Neuroscience 301, 90-105. doi: 10.1016/j.neuroscience.2015. 05.062

Neves, G., Cooke, S. F., and Bliss, T. V. (2008). Synaptic plasticity, memory and the hippocampus: a neural network approach to causality. Nat. Rev. Neurosci. 9, 65-75. doi: 10.1038/nrn2303

Nicolai, J., Burbassi, S., Rubin, J., and Meucci, O. (2010). CXCL12 inhibits expression of the NMDA receptor's NR2B subunit through a histone deacetylase-dependent pathway contributing to neuronal survival. Cell Death Dis. 1:e33. doi: 10.1038/cddis.2010.10

Olton, D. S., and Samuelson, R. J. (1976). Remembrance of places passed: spatial memory in rats. J. Exp. Psychol. Anim. Behav. Process. 2, 97-116. doi: 10.1037/0097-7403.2.2.97

Parameshwaran, K., Dhanasekaran, M., and Suppiramaniam, V. (2008). Amyloid beta peptides and glutamatergic synaptic dysregulation. Exp. Neurol. 210, 7-13 doi: 10.1016/j.expneurol.2007.10.008

Paxinos, G., and Watson, C. (2007). The Rat Brain in Stereotaxic Coordinates, 6th Edn. Amsterdam: Elsevier.

Pepeu, G., Grossi, C., and Casamenti, F. (2015). The brain cholinergic system in neurodegenerative diseases. Ann. Res. Rev. Biol. 6, 1-19. doi: 10.9734/ARRB/2015/14623

Poot, M., Teubert, H., Rabinovitch, P. S., and Kavanagh, T. J. (1995). De novo synthesis of glutathione is required for both entry into and progression through the cell cycle. J. Cell Physiol. 163, 555-560. doi: 10.1002/jcp.1041630316

Pushpalatha, B., Venumadhav, N., Swathi, M., and Raju, A., B. (2013). Neuroprotective effect of RSV against scopolamine induced cognitive impairment and oxidative stress in rats. Arch. Biol. Sci. 65, 1381-1386. doi: 10.2298/ABS1304381P

Rolf, S., Bettina, S., Carla, A., Rossella, B., Nail, B., Andrei, R., et al. (1998). Importance of the intracellular domain of NR2 subunits for NMDA receptor function in vivo. Cell 92, 279-289. doi: 10.1016/S0092-8674(00)80921-6

Rosales-Corral, S., Tan, D. X., Reiter, R. J., Valdivia-Velázquez, M., AcostaMartínez, J. P., and Ortiz, G. G. (2004). Kinetics of the neuroinflammationoxidative stress correlation in rat brain following the injection of fibrillar amyloid- $\beta$ onto the hippocampus in vivo. J. Neuroimmunol. 150, 20-28. doi: 10.1016/j.jneuroim.2004.01.005

Rotruck, J. T., Pope, A. L., and Ganther, H. E. (1973). Selenium: biochemical role as a compontent of GPx. Science 179, 558-590. doi: 10.1126/science.179.4073.588

Sahu, S. S., Madhyastha, S., and Rao, G. M. (2013). Neuroprotective effect of RSV against prenatal stress induced cognitive impairment and possible involvement of $\mathrm{Na}(+), \mathrm{K}(+)$-ATPase activity. Pharmacol. Biochem. Behav. 103, 520-525. doi: 10.1016/j.pbb.2012.09.012

Schmatz, R., Perreira, L. B., Stefanello, N., Mazzanti, C., Spanevello, R., Gutierres, J., et al. (2012). Effects of RSV on biomarkers of oxidative stress and on the activity of delta aminolevulinic acid dehydratase in liver and kidney of streptozotocin-induced diabetic rats. Biochimie 94, 374-383. doi: 10.1016/j.biochi.2011.08.005

Shen, J. -X., and Yake, J. L. (2009). Nicotinic acetylcholine receptor-mediated calcium signaling in the nervous system. Acta Pharmacol. Sin. 30, 673-680. doi: 10.1038/aps.2009.64

Sheng, M., and Kim, M. J. (2002). Postsynaptic signaling and plasticity mechanisms. Science 298, 776-780. doi: 10.1126/science.1075333

Soriano, F. X., Martel, M. A., Papadia, S., Vaslin, A., Baxter, P., Rickman, C., et al. (2008). Specific targeting of pro-death NMDA receptor signals with differing reliance on the NR2B PDZ ligand. J. Neurosci. 28, 10696-10710. doi: 10.1523/JNEUROSCI.1207-08.2008 
Tai, S. K., and Leung, L. S. (2012). Vestibular stimulation enhances hippocampal long-term potentiation via activation of cholinergic septohippocampal cells. Behav. Brain Res. 232, 174-182. doi: 10.1016/j.bbr.2012. 04.013

Viskontas, I. V., McAndrews, M. P., and Moscovitch, M. (2000). Remote episodic memory deficits in patients with unilateral temporal lobe epilepsy and excisions. J. Neurosci. 20, 5853-5857.

Wenk, G. L., Parsons, C. G., and Danysz, W. (2006). Potential role of Nmethyl-D-aspartate receptors as executors of neurodegeneration resulting from diverse insults: focus on memantine. Behav. Pharmacol. 17, 5-6. doi: 10.1097/00008877-200609000-00007

Wittmann, M., Bengtson, C. P., and Bading, H. (2004). "Extrasynaptic NMDA receptors: mediators of excitotoxic cell death," in Pharmacology of Cerebral Ischemia ed J. Krieglstein and S. Klumpp (Stuttgart: Medpharm Scientific Publishers), 253-266.

Yu, X., Wang, L. N., Ma, L., You, R., Cui, R., Ji, D., et al. (2012). Akebia saponin $\mathrm{D}$ attenuates IBO-induced cognitive deficits and pro-apoptotic response in rats: involvement of MAPK signal pathway. Pharmacol. Biochem. Behav. 101, 479-486. doi: 10.1016/j.pbb.2012.02.014

Zhang, H., Zhang, J., Ungvari, Z., and Zhang, C. (2009). RSV improves endothelial function: role of TNFa and vascular oxidative stress. Arterioscler. Thromb. Vasc. Biol. 29, 1164-1171. doi: 10.1161/ATVBAHA.109. 187146
Zhang, J., Li, P., Wang, Y., Liu, J., Zhang, Z., Cheng, W., et al. (2013). Ameliorative effects of a combination of baicalin, jasminoidin and cholic acid on IBO-Induced dementia model in rats. PLOS ONE 8:e56658. doi: 10.1371/journal.pone.0056658

Zhao, Y. N., Li, W. F., Li, F., Zhang, Z., Dai, Y. -D., Xu, A.-L., et al. (2013). Resveratrol improves learning and memory in normally aged mice through microRNA-CREB pathway. Biochem. Biophys. Res. Commun. 435, 597-602. doi: 10.1016/j.bbrc.2013.05.025

Zola, S. M., Squire, L. R., Teng, E., Stefanacci, L., Buffalo, E. A., et al. (2000). Impaired recognition memory in monkeys after damage limited to the hippocampal region. J. Neurosci. 20, 451-463.

Conflict of Interest Statement: The authors declare that the research was conducted in the absence of any commercial or financial relationships that could be construed as a potential conflict of interest.

Copyright (C) 2016 Karthick, Periyasamy, Jayachandran and Anusuyadevi. This is an open-access article distributed under the terms of the Creative Commons Attribution License (CC BY). The use, distribution or reproduction in other forums is permitted, provided the original author(s) or licensor are credited and that the original publication in this journal is cited, in accordance with accepted academic practice. No use, distribution or reproduction is permitted which does not comply with these terms. 